TITLE:

\title{
Work-hardening and twinning behaviors in a commercially pure titanium sheet under various loading paths
}

\section{$\operatorname{AUTHOR}(\mathrm{S}):$}

Hama, Takayuki; Nagao, Hirotaka; Kobuki, Akihiro; Fujimoto, Hitoshi; Takuda, Hirohiko

\section{CITATION:}

Hama, Takayuki ...[et al]. Work-hardening and twinning behaviors in a commercially pure titanium sheet under various loading paths. Materials Science and Engineering: A 2015, 620: 390-398

\section{ISSUE DATE:}

2015-01-03

URL:

http://hdl.handle.net/2433/192489

\section{RIGHT:}

(C) 2014 Elsevier B.V.; This is not the published version. Please cite only the published version.; この論文は出版社版でありません。引用の際に は出版社版をご確認ご利用ください。 


\section{Elsevier Editorial System(tm) for Materials Science \& Engineering A Manuscript Draft}

Manuscript Number: MSEA-D-14-03234R1

Title: Work-Hardening and Twinning Behaviors in a Commercially Pure Titanium Sheet under Various Loading Paths

Article Type: Research Paper

Keywords: Commercially pure titanium sheet

Hexagonal close-packed structure

Work-hardening

Bauschinger effect

Twinning

Detwinning

Corresponding Author: Dr. Takayuki Hama, Dr. Eng.

Corresponding Author's Institution: Kyoto university

First Author: Takayuki Hama, Dr. Eng.

Order of Authors: Takayuki Hama, Dr. Eng.; Hirotaka Nagao; Akihiro Kobuki; Hitoshi Fujimoto, Dr. Eng; Hirohiko Takuda, Dr. Eng

Abstract: In this study, the work-hardening and twinning behaviors in a commercially pure titanium sheet were examined under various loading paths including reverse loading. The yield stress was identical between tension and compression, while the work-hardening was slightly larger during compression than during tension. These tendencies were the same in both the rolling and transverse directions. When the sheet was subjected to reverse loading, the Bauschinger effect was observed during both tension-compression and compression-tension. The tendency in the Bauschinger effect was nearly independent of the strain path tested in the present study. Concerning the twinning, the activities of $\{10-12\}$ tensile twinning, $\{11-22\}$ compressive twinning, and $\{11-21\}$ tensile twinning were observed during tension. Alternatively, during compression, the activity of $\{10-12\}$ tensile twinning was observed and was much larger than that during tension. When the sheet was subjected to tension following compression, detwinning occurred. Although the trend in the activity of twinning was similar to that of a magnesium alloy sheet, the behavior observed in the stress-strain curves was quite different from that of a magnesium alloy sheet. Based on the results presented, the effect of twinning and detwinning activities on the work-hardening behavior was discussed. 


\section{Work-Hardening and Twinning Behaviors in a Commercially Pure Titanium Sheet under Various Loading Paths}

Takayuki HAMA*

Hirotaka NAGAO

Akihiro KOBUKI

Hitoshi FUJIMOTO

Hirohiko TAKUDA

Department of Energy Science and Technology, Kyoto University, Yoshida-honmachi,

Sakyo-ku, Kyoto 606-8501, Japan

Keywords: Commercially pure titanium sheet

Hexagonal close-packed structure

Work-hardening

Bauschinger effect

Twinning

Detwinning 
Corresponding author: Takayuki HAMA

Department of Energy Science and Technology, Kyoto University

Yoshida-Honmachi, Sakyo-ku, Kyoto 606-8501, Japan

TEL: $\quad+81-(0) 75-753-5418$

FAX: $\quad+81-(0) 75-753-5428$

E-mail: $\quad \underline{\text { hama@energy.kyoto-u.ac.jp }}$

\section{Abstract}

In this study, the work-hardening and twinning behaviors in a commercially pure titanium sheet were examined under various loading paths including reverse loading. The yield stress was identical between tension and compression, while the work-hardening was slightly larger during compression than during tension. These tendencies were the same in both the rolling and transverse directions. When the sheet was subjected to reverse loading, the Bauschinger effect was observed during both tension-compression and compression-tension. The tendency in the Bauschinger effect was nearly independent of the strain path tested in the present study. Concerning the twinning, the activities of $\{10 \overline{1} 2\}$ tensile twinning, $\{11 \overline{2} 2\}$ compressive twinning, and 
$\{11 \overline{2} 1\}$ tensile twinning were observed during tension. Alternatively, during compression, the activity of $\{10 \overline{1} 2\}$ tensile twinning was observed and was much larger than that during tension. When the sheet was subjected to tension following compression, detwinning occurred. Although the trend in the activity of twinning was similar to that of a magnesium alloy sheet, the behavior observed in the stress-strain curves was quite different from that of a magnesium alloy sheet. Based on the results presented, the effect of twinning and detwinning activities on the work-hardening behavior was discussed. 


\section{Introduction}

With properties such as low density, high corrosion resistance, and high heat resistance, commercially pure titanium (hereafter referred to as $\mathrm{CP}-\mathrm{Ti}$ ) is widely used in various applications such as chemical plants, heat exchangers, and chassis of mobile phone and computer [1-3]. CP-Ti sheets have high ductility at room temperature, therefore they are often manufactured at room temperature by press forming and bending.

Alternatively, it is also well known that rolled CP-Ti sheets demonstrate strong anisotropic deformation behavior. For instance, their Lankford value ( $r$-value), i.e., the ratio between the width and thickness strains, is very high and it differs notably between the rolling direction (RD) and the transverse direction (TD) [2-4]. In addition, the work-hardening behavior exhibited by rolled CP-Ti sheets differs between tension and compression [3-7] as well as between the RD and the TD [3,4,6,8,9]. Among the previous examples, the high $r$-value is advantageous for press forming because this yields good deep drawability. Alternatively, because of the strong anisotropy observed between tension and compression and between the RD and the TD, it is recognized that press forming of CP-Ti sheets is quite difficult.

The strong anisotropy in CP-Ti sheets is because of the strong crystal anisotropy of 
the hexagonal close-packed (hereafter referred to as hcp) structure and the strong basal texture with $c$-axes tilted between $20^{\circ}$ to $40^{\circ}$ from the normal direction (ND) to the TD $[2,3,6,7,9,10]$. In CP-Ti sheets at room temperature, $\{10 \overline{1} 0\}<11 \overline{2} 0>$ prismatic slip is the easiest family to be activated, however $(0001)<11 \overline{2} 0>$ basal slip and $\{10 \overline{1} 1\}$ $<11 \overline{2} 0>$ pyramidal slip are also active [10-16]. Alternatively, because there are only four independent slip systems in the three previously mentioned families, at least one other independent deformation mode is necessary to satisfy the von Mises criterion [17]. From earlier studies, it is known that $\{10 \overline{1} 1\}<11 \overline{2} 3>$ pyramidal slip, $\{11 \overline{2} 2\}<11 \overline{2} 3\rangle$ pyramidal slip [18-22], or twinning [2, 9, 10, 19, 23, 24, 25] may act as the additional deformation mode.

In polycrystalline $\mathrm{CP}-\mathrm{Ti}$, the activity of several twin modes has been reported: $\{10 \overline{1} 2\},\{11 \overline{2} 1\}$, and $\{11 \overline{2} 3\}$ tensile twinning, and $\{11 \overline{2} 2\},\{10 \overline{1} 1\}$, and $\{11 \overline{2} 4\}$ compressive twinning $[9,10,19]$. Among them, at room temperature the activities of $\{10 \overline{1} 2\}$ tensile twinning and $\{11 \overline{2} 2\}$ compressive twinning are most common compared to the other twinning modes. Chun et al. [23] reported that $\{10 \overline{1} 1\}$ compressive twinning and $\{11 \overline{2} 1\}$ tensile twinning were difficult to activate because of a large shuffling parameter and high twinning shear strain, respectively. Paton et al. [19] also demonstrated that the activity of $\{10 \overline{1} 1\}$ compressive twinning was negligible at 
temperatures below $300^{\circ} \mathrm{C}$. Murayama et al. [24] concluded from their experiments that $\{10 \overline{1} 2\}$ tensile twinning and $\{11 \overline{2} 2\}$ compressive twinning were observed, whereas $\{11 \overline{2} 3\}$ tensile twinning and $\{11 \overline{2} 4\}$ compressive twinning were not observed under uniaxial tension at room temperature.

Mullins et al. [9] examined active twin modes during uniaxial, plane strain, and equibiaxial tension in a rolled $\mathrm{CP}-\mathrm{Ti}$ sheet. Under uniaxial tension along the RD, $\{11 \overline{2} 2\}$ compressive twinning and $\{11 \overline{2} 4\}$ compressive twinning were active, whereas under uniaxial tension along the TD $\{10 \overline{1} 2\}$ tensile twinning was also active. These results were similar to those reported by Ishiyama et al. [2]. The active twin modes under plane strain and equibiaxial tension were also similar to those of uniaxial tension; however, the volume fraction of twinned area was much larger than that of uniaxial tension. Stanford et al. [26] conducted a compression test in a wire-drawn CP-Ti sample and depicted that $\{10 \overline{1} 2\}$ tensile twinning was the most active twin mode and $\{11 \overline{2} 2\}$ compressive twinning and $\{11 \overline{2} 1\}$ tensile twinning were also active. They also reported that $\{11 \overline{2} 2\}$ compressive twinning was very sensitive to grain size. Ghaderi and Barnett [27] also examined the sensitivity of twinning to grain size in CP-Ti. Bozzolo et al. [28] observed misorientations induced by twinning during cold rolling in $\mathrm{CP}-\mathrm{Ti}$ and showed that $\{11 \overline{2} 2\}$ compressive twinning was very active and $\{10 \overline{1} 2\}$ tensile twinning and 
$\{11 \overline{2} 1\}$ tensile twinning were also active. Tirry et al. [29] carried out a monotonic simple shear test in a CP-Ti plate and presented that $\{10 \overline{1} 2\}$ tensile twinning could be activated easier than $\{11 \overline{2} 2\}$ compressive twinning. Deng et al. [30] reported a similar result. Li et al. [31] investigated the activity of $\{11 \overline{2} 1\}$ tensile twinning under tension in a CP-Ti plate and reported that the activity of $\{11 \overline{2} 1\}$ tensile twinning was much less than that of $\{10 \overline{1} 2\}$ tensile twinning. Murasawa et al. [7] performed the uniaxial tensile test on a rolled $\mathrm{CP}-\mathrm{Ti}$ sheet and found that the twinning nucleated and grew around the yield point. This successive twin nucleation around the yield point was pronounced when the angle between the tensile and rolling direction was smaller than $30^{\circ}$. Becker et al. [32] examined the work-hardening behavior under tension in a rolled CP-Ti sheet. The authors identified three different work-hardening stages depending on the work-hardening rate and explained the dominant mechanism as follows. Plastic deformation was dominated primarily by prismatic and basal slip and additionally by pyramidal $\langle\mathrm{a}+\mathrm{c}\rangle$ slip in the first stage, whereas $\{11 \overline{2} 2\}$ compressive twinning and $\{10 \overline{1} 2\}$ tensile twinning were active in the second and third stages, respectively. Mullins et al. [9] also reported that twinning was active only at the latter stage of deformation under tension.

As described earlier, extensive studies have been conducted to identify the twinning 
activity in CP-Ti sheets. Considering strong basal texture is generally developed in CP-Ti sheets, the active twin mode may be different between tension and compression. However, to the best of our knowledge, the identification of the twinning activity has been done under either tension or compression but a comparison between tension and compression has not yet been examined. Ishiyama et al. [2] investigated the activity of twinning under uniaxial tension and compression in the RD in a polycrystalline $\mathrm{CP}-\mathrm{Ti}$ sheet theoretically. They depicted that $\{11 \overline{2} 2\}$ compressive twinning could be activated under tension, while $\{10 \overline{1} 2\}$ and $\{11 \overline{2} 1\}$ tensile twinning would be active under compression. However, their discussion was based only on the Schmid factor and was not verified experimentally.

In rolled magnesium (hereafter referred to as $\mathrm{Mg}$ ) alloy sheets that also have the hcp structure, it is well known that $\{10 \overline{1} 2\}$ tensile twinning is active when the sheet is subjected to in-plane compression. That twinning activation occurs because of the strong basal texture of the $\mathrm{Mg}$, however detwinning is easily activated when the loading direction is inverted to tension [33-43]. The activities of twinning and detwinning play important roles in deformation behavior such as work-hardening under reverse loading and the nonlinearity in the stress-strain curve during unloading; thus they have been investigated extensively both experimentally and theoretically [44-47]. Based on the 
large activity of twinning in CP-Ti sheets observed in the earlier parts of this study, it would be expected that the detwinning would also be active under reverse loading in CP-Ti sheets. Moreover, detwinning has been reported in Ti alloys with a body-centered cubic structure [48, 49]. However, to the best of our knowledge, studies on the deformation behavior upon strain path changes in CP-Ti sheets are scarce; hence, the activity of detwinning upon strain path changes has not been observed. Shamsaei et al. [50] and Peng et al. [51] performed fatigue tests in CP-Ti and examined the stress-strain behavior and the fatigue life in detail. Alternatively, the activity of twinning was not investigated in their studies. Tritschler et al. [52] conducted a cyclic loading test in a $\mathrm{Ti}$ alloy sheet with hcp structure and modeled the work-hardening behavior. However, microstructure upon cyclic loading was not observed; hence, the occurrence of detwinning and the effect of twinning activity on the work-hardening behavior upon cyclic loading are not yet understood. Because sheets are often subjected to reverse loading such as bending-unbending in press forming, it is worth examining the occurrence of detwinning and the deformation behavior of CP-Ti sheets upon strain path changes.

The present study investigates the work-hardening and twinning behaviors in a $\mathrm{CP}-\mathrm{Ti}$ sheet under in-plane tension, compression, compression followed by tension 
(hereafter referred to as compression-tension), and tension followed by compression (hereafter referred to as tension-compression). In particular, the occurrence of detwinning upon reverse loading is examined carefully. To this end, the stress-strain curves and the microstructure evolution using electron backscatter diffraction (hereafter referred to as EBSD) are investigated in detail.

2. Experimental details

\subsection{Material}

A cold rolled CP-Ti sheet (Kobe Steel, JIS grade 2) with $1 \mathrm{~mm}$ thickness was used in the present study. A specimen shown in Fig.1 was machined parallel to the RD or the TD. A specimen cut parallel to the RD or the TD is hereafter referred to as the RD sample or the TD sample, respectively. The samples were annealed for approximately 1 hour at $530^{\circ} \mathrm{C}$ before testing. The average grain size was approximately $20 \mu \mathrm{m}$.

\subsection{Experimental procedure}

Testing was performed in in-plane monotonic tension, monotonic compression, compression-tension, and tension-compression. To prevent buckling during compression, comb-shaped dies were used during testing to provide a compressive force 
in the thickness direction of the sample [34, 35, 53]. Figure 2 depicts the schematic diagrams of the experimental apparatus and the comb-shaped dies. Mineral hydraulic oil with a nominal kinematic viscosity of $32 \mathrm{cSt}$ at $40^{\circ} \mathrm{C}$ was used to provide lubrication between the comb-shaped dies and the sample. A hydraulic pump delivered the compressive force in the thickness direction. The magnitude of the through-thickness stress was $9 \mathrm{MPa}$ or approximately $3 \%$ of the yield stress of the CP-Ti sheet. The magnitude of compressive force was determined to suppress buckling and to minimize the influence of friction between the dies and specimen as much as possible. Further, because it was difficult to optimize the lubrication condition between CP-Ti sheets and dies [2], the effect of friction on the stress-strain curve could not be removed completely in the present study. However, the qualitative tendency observed in the results remained unchanged irrespective of the variability in the friction condition; thus, it is still worthwhile to examine them.

The tests were conducted at an initial strain rate of $6.67 \times 10^{-4} / \mathrm{s}^{-1}$ at room temperature [34, 35, 54]. Longitudinal strains were measured using a strain gauge (Kyowa Electronic Instruments, KFEM series). It should be noted that after every strain of several percent, a new strain gauge replaced the one in use. This replacement was made because it was observed that the strain gauge could easily become detached from 
the CP-Ti sheet.

An evolution of $r$-value was also measured under tension to examine the plastic anisotropy of the material. The $r$-value was calculated in the form

$$
r=\frac{\varepsilon_{w}}{\varepsilon_{t}}=-\frac{\varepsilon_{w}}{\left(\varepsilon_{l}+\varepsilon_{w}\right)}
$$

where $\varepsilon_{l}, \varepsilon_{w}$, and $\varepsilon_{t}$ are the strains in the length, width, and thickness directions, respectively.

After the mechanical tests were conducted, the EBSD analysis was used to observe microstructures of the deformed specimens to investigate the activities of twinning and detwinning. The cross-sectional surface perpendicular to the loading direction of the deformed specimen was polished using a cross-section polisher. The EBSD analysis was performed with a step size of $1.0 \mu \mathrm{m}$ in all conditions. After EBSD patterns were measured, a pole figure and an inverse pole figure were analyzed using OIM-Analysis 7 (TSL Solutions). It should be noted that measured data whose confidence index was smaller than 0.1 was excluded before the measured result was analyzed.

3. Results and discussion

3.1 Stress-strain curves

In this section, the stress-strain curves under various loading paths are investigated. 
First, the results of the RD sample are described.

The stress-strain curves obtained from the monotonic tension and compression tests are shown in Fig. 3, wherein the true stress and logarithmic strain are expressed in absolute values. Because a new strain gauge replaced the one in use as described in section 2.2 , the sheets were once unloaded at strain of approximately 0.05 in all conditions. A comparison of the tension and compression curves reveals that the same yield stress is achieved under both conditions, whereas the work-hardening is slightly larger under compression than under tension. This result exhibits the asymmetry between tension and compression and is similar to another finding also reported in the literature [6].

A variation of work-hardening rate as a function of flow stress $[32,55]$ is used to investigate the work-hardening in detail. The work-hardening rate was calculated using two points for every five-hundred successive data points or a strain increment of approximately 0.003 . Figure 4 displays the results during tension and compression for the RD and the TD samples. It should be noted that only the results in the plastic deformation range are discussed. Under both tension and compression, the work-hardening rate decreases sharply at the beginning of plastic deformation and then the slopes flatten at moderate strains. A difference in the variations of the 
work-hardening rate obtained between tension and compression is very small as also observed in Fig. 4. Becker et al. [32] reported that three different stages could be distinguished in the variation of work-hardening rate; however, in Fig. 4 only two stages, i.e., the initial sharp decrease and the following gradual decrease, are observed. This difference from the result reported by Becker et al. may be because of the difference in the strain range examined. Becker et al. investigated the deformation until the necking arose, whereas in the present study the deformation up to an absolute strain of $10 \%$ was examined.

Figures 5 (a) and 5 (b) depict the stress-strain curves obtained under compression-tension and tension-compression, respectively. In both cases, the amount of strain imparted during the first loading was approximately 0.05. For direct comparison of the results between tension-compression and compression-tension, Fig. 5 (c) shows the results for cases where the signs of stress and strain for tension-compression were inverted. In the following figures, compression-tension and tension-compression are denoted by CT and TC, respectively. In both results, the yield stresses after the loading direction was inverted are much smaller than the flow stresses before the loading direction was inverted, thereby exhibiting a strong Bauschinger effect under both compression-tension and tension-compression. The stress-strain curves after 
the loading direction was inverted under tension-compression and compression-tension are very similar.

Figure 6 demonstrates the variation of the work-hardening rate during tension-compression and compression-tension after the loading direction was inverted.

In both conditions, the decrease in the work-hardening rate at the beginning of plastic deformation is more gradual than that observed under the monotonic loading paths (Fig. 4). Moreover, the two different stages in the slope observed in Fig. 4 are unclear. These differences between the monotonic loading and the reverse loading may be because of the Bauschinger effect.

Next, the results of the TD sample are described focusing on the difference from the results of the RD sample. Under monotonic tension (Fig.3), the yield stress is larger but the work-hardening is smaller in the TD sample than in the RD sample. Under compression, the yield stress in the TD sample is still larger than in the RD sample, whereas the work-hardening is similar to that in the RD sample. Comparing the results in the TD sample between tension and compression, the yield stress under compression is comparable to that under tension, whereas the work-hardening is larger under compression than under tension. The difference in the work-hardening can also be observed in the variation of the work-hardening rate (Fig. 4). 
When the sheet is subjected to the strain-path change, the Bauschinger effect also arises in the TD sample (Fig. 5). Therefore, the initial decrease in the work-hardening rate is more gradual than that under monotonic loading as in the case of the RD sample (Fig. 6). The flow stresses during tension-compression and compression-tension are slightly larger under the TD sample than under the RD sample. This result is consistent with that observed under monotonic loading (Fig. 3). Comparing the results in the TD sample between compression-tension and tension-compression (Fig. 5 (c)), the work-hardening after the loading direction was inverted is larger under tension-compression than under compression-tension. This trend is the same as that observed during monotonic loading shown in Fig. 3.

Fig. 7 shows the evolutions of $r$-value under tension. The $r$-value is notably larger for the TD sample than that of the RD sample. This tendency is consistent with the results reported in the literature [2-4].

The results obtained are summarized here. The CP-Ti sheet demonstrated small in-plane anisotropy under both tension and compression; however, the characteristics of the anisotropy differed between tension and compression. Such in-plane anisotropy of CP-Ti sheets has been reported in many studies $[3,4,6,8,9]$ although characteristics of anisotropy were somewhat different depending on materials used. It was also found 
that during reverse loading a strong Bauschinger effect occurred regardless of the conditions. Moreover, the work-hardening behavior after the loading direction was inverted tended to be similar to that of monotonic loading, indicating that the effect of reverse loading on the work-hardening behavior would be small except for the occurrence of the Bauschinger effect.

\subsection{The Bauschinger effect}

In this section, the Bauschinger effect observed in the CP-Ti sheet is examined more in detail. The results of the RD sample are used to examine the tendency.

Figure 8 (a) displays the stress-strain curves obtained under compression-tension with compressive strains of approximately $0.02,0.05$, and 0.1 . The result with a compressive strain of 0.05 is the same as that shown in Fig. 5. Early re-yielding and a transient Bauschinger effect [56] are observed irrespective of the amount of compressive strain, and the tendency in the transient Bauschinger effect seems to be similar regardless the amount of compressive strain. Fig. 8 (b) presents the results obtained under tension-compression with tensile strains of approximately $0.02,0.05$, and 0.1. It should be noted that the sheet was once unloaded for the replacement of the strain gauge in the test with tensile strain of approximately 0.1. Similar to 
compression-tension, early re-yielding and a transient Bauschinger effect are also exhibited under these conditions. The tendency observed under tension-compression is very similar to that of compression-tension. To examine this similarity in detail, Fig. 8 (c) shows the results for cases where the signs of stress and strain are inverted in the results of tension-compression. The stress-strain curves obtained under tension-compression are noticeably in good agreement with those of compression-tension except that the work-hardening is slightly larger under compression than tension. This result indicates that the tendency in the Bauschinger effect is almost independent of the sequence of tension and compression.

\subsection{Microstructural observation}

The results of the RD sample were used to examine the deformation behavior from a microscopic point of view using the EBSD analysis. The microstructures were observed after unloading at points $\mathrm{O}, \mathrm{A}, \mathrm{B}, \mathrm{C}$, and D as indicated in Figs. 8 (a) and 8 (b). The pole figures and the inverse pole figures at these points are shown in Figs. 9 and 10, respectively. To investigate the activity of twinning, the figures where only twin boundaries were extracted from the inverse pole figure maps are also shown in Fig. 10. The extracted twinning systems are $\left\{\begin{array}{lllll}1 & 0 & \overline{1} & 2\end{array}\right\}$ and $\left\{\begin{array}{lllll}1 & 1 & \overline{2} & 1\end{array}\right\}$ tensile twinning and 
$\left\{\begin{array}{lll}1 & 1 & \overline{2} \\ 2\end{array}\right\}$ compressive twinning. The other twin modes were rarely observed in this study. It should be noted that the dots observed on the maps are the result of noise; hence, they are neglected in the following discussion.

The initial microstructures (point O, Figs. 9 (a) and 10 (a)) are as follows. Two peaks tilted $20^{\circ}$ to $30^{\circ}$ from the ND to the TD are observed in the (0001) pole figure, while a strong peak is not observed in the $\left(\begin{array}{llll}1 & 0 & \overline{1} & 0\end{array}\right)$ pole figure. The orientation of the $\left(\begin{array}{llll}1 & 0 & \overline{1} & 0\end{array}\right)$ direction is approximately perpendicular to the ND. These are the typical cold rolling texture of a CP-Ti sheet $[2,3,6,7,9,10]$. Twin boundaries are rarely observed in the inverse pole figure map, indicating that the twinning does not occur in the initial texture.

When tensile deformation was imparted from point $\mathrm{O}$ to point $\mathrm{A}$, the (0001) pole figure remained almost unchanged, whereas in the $\left(\begin{array}{llll}1 & 0 & \overline{1} & 0\end{array}\right)$ pole, relatively strong peaks tend to appear around the RD (Fig. 9 (b)). The presented results are consistent with those reported by Becker et al. [32]. As shown in Fig. 10 (b), the activities of $\left\{\begin{array}{llll}1 & 1 & \overline{2} & 2\end{array}\right\}$ compressive twinning and $\left\{\begin{array}{lllll}1 & 0 & \overline{1} & 2\end{array}\right\}$ tensile twinning are observed. To a more limited extent, $\left\{\begin{array}{llll}1 & 1 & \overline{2} & 1\end{array}\right\}$ tensile twinning is also observed. Among the twin modes, $\{11 \overline{2} 2\}$ compressive twinning seems to be the most active. This result is similar to those reported in the literature [9, 19, 23, 24]. 
When compressive deformation was applied from point $\mathrm{O}$ to point $\mathrm{B}$, two peaks appear around the $\mathrm{RD}$ in the (0001) pole figure, while six peaks tend to appear perpendicular to the ND in the $\left(\begin{array}{llll}1 & 0 & \overline{1} & 0\end{array}\right)$ pole figure (Fig. 9 (c)). Meanwhile,

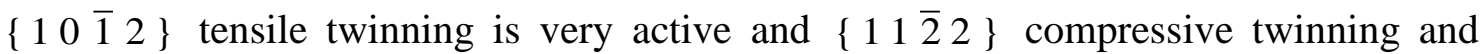
$\left\{\begin{array}{lll}1 & 1 & 2 \\ 1\end{array}\right\}$ tensile twinning are also observed to a small extent as shown in Fig. 10 (c). The lattice rotation induced by the activity of $\left\{\begin{array}{llll}1 & 0 & \overline{1} & 2\end{array}\right\}$ tensile twinning is approximately $84.8^{\circ}$, therefore the $c$-axes of grains, which are tilted $20^{\circ}$ to $30^{\circ}$ from the ND to the TD, would be rotated to the vicinity of the RD when $\left\{\begin{array}{llll}1 & 0 & \overline{1} & 2\end{array}\right\}$ tensile twinning is activated. Accordingly, the peaks observed around the RD in the (0001) pole figure at point $\mathrm{B}$ may be caused by the activity of $\left\{\begin{array}{llll}1 & 0 & \overline{1} & 2\end{array}\right\}$ tensile twinning. Warwick et al. [16] also reported a similar result.

As described in the previous results, the $\left\{\begin{array}{llll}1 & 1 & \overline{2} & 2\end{array}\right\}$ compressive twinning and the $\left\{\begin{array}{llll}1 & 0 & \overline{1} & 2\end{array}\right\}$ tensile twinning are the most active modes under tension (Fig. 10 (b)) and compression (Fig. 10 (c)), respectively. The active twinning mode in tension is notably different from that in compression. This result can be understood in that the stresses that act along the $c$-axes become negative and positive under tension and compression, respectively, because of the strong basal texture. Alternatively, the activity of $\left\{\begin{array}{llll}1 & 0 & \overline{1} & 2\end{array}\right\}$ tensile twinning under compression is notably larger than that of $\left\{\begin{array}{llll}1 & 1 & \overline{2} & 2\end{array}\right\}$ 
compressive twinning under tension. In the typical rolling texture shown in Fig. 9 (a), the Schmid factor for $\left\{\begin{array}{llll}1 & 1 & \overline{2} & 2\end{array}\right\}$ compressive twinning under tension may be higher than that of $\left\{\begin{array}{lllll}1 & 0 & \overline{1} & 2\end{array}\right\}$ tensile twinning under compression [2], and this result indicates that the critical resolved shear stress for $\left\{\begin{array}{llll}1 & 1 & \overline{2} & 2\end{array}\right\}$ compressive twinning would also be higher than that of $\left\{\begin{array}{lllll}1 & 0 & \overline{1} & 2\end{array}\right\}$ tensile twinning. Moreover, because the activity of

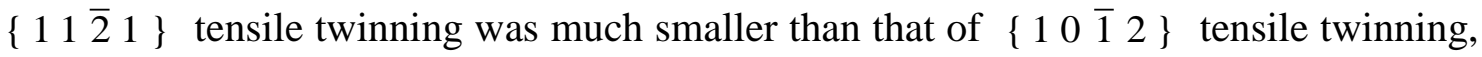
this result suggests that $\left\{\begin{array}{llll}1 & 0 & \overline{1} & 2\end{array}\right\}$ tensile twinning may be the most easily activated twinning mode in the examined CP-Ti sheet. These observations are consistent with observations reported in the literature $[10,25]$.

When the sheet was subjected to tension following compression from point B to points $\mathrm{C}$ and $\mathrm{D}$, the two peaks observed around the $\mathrm{RD}$ in the (0001) pole figure during compression (Fig. 9 (c)) are not visible (Figs. 9 (d), and 9 (e)). At the same time, the number of the boundaries of the $\left\{\begin{array}{llll}1 & 0 & \overline{1} & 2\end{array}\right\}$ tensile twinning tends to decrease as the tensile strain increases (Figs. 10 (c), 10 (d), and 10 (e)). These tendencies observed in the pole figure and the twin boundaries are very similar to those observed in rolled $\mathrm{Mg}$ alloy sheets subjected to reverse loading [33-44], indicating that the $\left\{\begin{array}{lllll}1 & 0 & 1 & 2\end{array}\right\}$ detwinning is activated also in the CP-Ti sheet.

In the $\left(\begin{array}{llll}1 & 0 & \overline{1} & 0\end{array}\right)$ pole figures, six peaks observed during compression (Fig. 9 (c)) 
gradually become unclear as the tensile strain increases, and consequently, two peaks tend to arise around the RD (Figs. 9 (d) and 9 (e)). This tendency observed at point D is similar to those observed under monotonic tension (Fig. 9 (b)).

As described in the discussion of Figs. 9 and 10, the CP-Ti sheet showed the similar tendency with that of a rolled magnesium alloy sheet [33-44] where the $\left\{\begin{array}{lllll}1 & 0 & \overline{1} & 2\end{array}\right\}$ tensile twinning was active under in-plane compression and the detwinning was active when the sheet was subjected to reverse loading from compression to tension. Recently such twinning-detwinning characteristics are used to develop a magnesium alloy sheet with weak texture [57]. The contribution of a strong basal texture to the strong anisotropy observed in CP-Ti sheets $[2,3,6,7,9,10]$, along with the preceding results, suggests that a similar method may be applicable to develop a CP-Ti sheet with a weak texture.

3.4 Effect of twinning activity on the stress-strain curve

In a rolled magnesium alloy sheet, because the critical resolved shear stress of the $\left\{\begin{array}{llll}1 & 0 & \overline{1} & 2\end{array}\right\}$ tensile twinning is lower than that of nonbasal slip, the activities of twinning and detwinning considerably affect the stress-strain curve. For example, the yield stress under compression is smaller than that of tension, a plateau region with relatively low 
flow stress arises in the early stage of compression, and a sigmoidal curve occurs during tension following compression [33-44].

Alternatively, in the CP-Ti sheet the relationship between the twinning and detwinning activities and the work-hardening behavior seems to be different from that of a rolled magnesium alloy sheet. As explained in sections 3.1 and 3.3, the twinning activity is more pronounced under compression than under tension as in the case of a rolled magnesium alloy sheet, but at the same time the yield stress is almost the same between tension and compression and the work-hardening is slightly larger under compression than under tension. Moreover, the detwinning was observed when the sheet was subjected to compression-tension, but the stress-strain curve during tension following compression shows a monotonic increasing trend.

The detected differences in the effect of twinning and detwinning activities on the stress-strain curve between the CP-Ti sheet and a rolled magnesium alloy sheet may be related to the difference in the critical resolved shear stress of twinning. For Ti, it was reported that the critical resolved shear stress of twinning was larger than that of prismatic and basal slip [16, 58, 59]. Therefore, unlike in a rolled magnesium alloy sheet, the twinning experience in a $\mathrm{Ti}$ sheet tended to be active in the latter stage of deformation and larger work-hardening could be attained when the twinning was 
activated $[8,24,60,61]$. In fact, the prior observation reported in the literature is consistent with the present results in which the work-hardening is slightly larger under compression than under tension.

Additionally, the difference in the critical resolved shear stress of twinning may also yield the difference in the magnitude of the twinning activity between the CP-Ti and magnesium alloy sheets. Comparison of the pole figures after the sheets of CP-Ti (Fig. 9 (c)) and rolled magnesium alloy [33] were subjected to compression reveals that twinning activity is smaller in the CP-Ti than in the magnesium alloy. The smaller activity of twinning in the $\mathrm{CP}-\mathrm{Ti}$ sheet could cause the effect of twinning and detwinning activities on the stress-strain curve to be smaller than that of the magnesium alloy sheet. This premise is supported by the fact that in CP-Ti the amount of plastic deformation contributed by twinning is much smaller than that by the activity of slip systems as reported in the literature $[13,14]$. The previous presumption is also consistent with the results that the difference in the work-hardening between tension and compression was small and that a significant difference was not observed in the stress-strain curves between compression-tension and tension-compression (Fig. 8 (c)) although the twinning and detwinning activities were notably different between tension and compression. The latter result further suggests that the effect of detwinning on the 
stress-strain curve may be negligible within the experimental conditions tested in the present study.

If the proposed mechanisms are valid, the twinning activity under compression may also be large in the TD sample because the work-hardening under compression was large as well as in the RD sample (Fig. 3). To examine this premise, the microstructures were observed after the TD sample was compressed to a strain of about -0.1 , which corresponds to point B in Fig. 8 (a). The results are shown in Fig. 11. The twinning activity was notably much smaller than that in the RD sample (Figs. 9 (c) and 10 (c)). Indeed, the difference in the twinning activity between the RD and the TD samples observed in the present study is consistent with an analysis using Schmid factor reported by Ishiyama et al. [2]. In that study, the authors suggested that theoretically, the activity of $\left\{\begin{array}{llll}1 & 0 & \overline{1} & 2\end{array}\right\}$ tensile twinning under compression might be much smaller in the TD sample than in the RD sample. This observation aligns well with those of other researchers and indicates that the large work-hardening attained under compression in both the RD and the TD samples would be attributable not only to the twinning activity but also to other factors $[13,62]$. Roth et al. [62] recently presumed that the difference in the work-hardening between the RD and the TD might be explained by the slip activity. A similar discussion may be applicable to explain the difference between 
tension and compression. Further investigation is necessary to understand the effect of twinning activity on the stress-strain curve in detail.

\section{Conclusion}

In the present study, the deformation behavior in a commercially pure titanium sheet was examined under monotonic tension, monotonic compression, tension followed by compression, and compression followed by tension. The stress-strain curves and the microstructure observation using EBSD analysis were used to investigate the work-hardening and twinning behaviors under the aforementioned conditions. Specimens cut parallel to the rolling direction were primarily used. The following conclusions were obtained:

(1) The yield stress is nearly the same in both tension and compression, while the work-hardening is slightly larger during compression than tension. When the sheet is subjected to reverse loading, early re-yielding and a transient Bauschinger effect are exhibited both during tension following compression and compression following tension. In this study, the tendency of the stress-strain curve upon reverse loading is almost independent of the sequence of tension and compression.

(2) The activities of the $\left\{\begin{array}{llll}1 & 0 & \overline{1} & 2\end{array}\right\}$ tensile twinning, $\left\{\begin{array}{lll}1 & 1 & \overline{2} \\ 2\end{array}\right\}$ compressive 
twinning, and $\left\{\begin{array}{llll}1 & 1 & \overline{2} & 1\end{array}\right\}$ tensile twinning are observed during tension. Alternatively, during compression, the activity of $\left\{\begin{array}{llll}1 & 0 & \overline{1} & 2\end{array}\right\}$ tensile twinning is observed and it is much larger than that during tension. These results demonstrate that the active twin modes and their activities are different between tension and compression. When the sheet is subjected to tension following compression, $\left\{\begin{array}{llll}1 & 0 & \overline{1} & 2\end{array}\right\}$ detwinning is observed.

(3) The tendency that the $\left\{\begin{array}{llll}1 & 0 & \overline{1} & 2\end{array}\right\}$ twinning and detwinning are active during compression and tension following compression, respectively, is similar to that of a magnesium alloy sheet that has the hexagonal close-packed structure as well as the commercially pure titanium sheet. Alternatively, the effect of twinning and detwinning activities on the work-hardening behavior would be significantly different from that of the magnesium alloy sheet. One of the reasons for this difference may be that the critical resolved shear stress is larger in the titanium sheet than the magnesium alloy sheet. This eventually leads to the trend that the activities of twinning and detwinning are smaller in the titanium sheet than that in the magnesium alloy sheet.

(4) When the sheet is subjected to compression in the transverse direction, the work-hardening is slightly larger than that under tension as in the case of the deformation in the rolling direction. Conversely, the activity of twinning is much 
smaller in the transverse direction than that in the rolling direction. This result indicates that the slightly larger work-hardening observed under compression rather than tension is attributable not only to twinning activity but also to other factors. This finding will be investigated in our future work.

\section{Acknowledgements}

The authors wish to acknowledge Dr. Tsutomu Tanaka and Dr. Takashi Nishimura of Technology Research Institute of Osaka Prefecture for their help with the EBSD analysis. This work was partially supported by JSPS KAKENHI Grant Number 26289271 and the Photon and Quantum Basic Research Coordinated Development Program from the Ministry of Education, Culture, Sports, Science and Technology, Japan.

References

[1] M. Usuda, M. Ishii, Titanium Japan, 52 (2004), 110-116 (in Japanese).

[2] S. Ishiyama, Titanium Japan, 54 (2006), $42-51$ (in Japanese).

[3] M. Ishiki, T. Kuwabara, Y. Hayashida, Int. J. Mater. Form., 4 (2011), 193-204.

[4] T. Kuwabara, C. Katami, M. Kikuchi, T. Shindo, T. Ohwue, Proc. NUMIFORM 
2001 (2001), 781-787.

[5] D. Lee, W.A. Backofen, Trans. Metall. Soc. AIME, 236 (1966), 1077-1084.

[6] M.E. Nixon, O. Cazacu, R.A. Lebensohn, Int. J. Plasticity, 26 (2010), 516-532.

[7] G. Murasawa, T. Morimoto, S. Yoneyama, Exp. Mech., 52 (2012), 503-512.

[8] M. Ogaya, M. Kisaichi, S. Ishiyama, Tetsu-to-Hagane, 72 (1986), 649-656 (in Japanese).

[9] S. Mullins, B.M. Patchett, Metall. Trans. A, 12 (1981), 853-863.

[10] H. Conrad, Progress in Mater. Sci., 26 (1981), 123-403.

[11] F.D. Rosi, C.A. Dube, B.H. Alexander, J. Metals, 5 (1953), 257-265.

[12] E.A. Anderson, D.C. Jillson, S.R. Dunbar, J. Metals, 5 (1953), 1191-1197.

[13] S. Nemat-Nasser, W.G. Guo, J.Y. Cheng, Acta Mater., 47 (1999), 3705-3720.

[14] D.R. Chichili, K.T. Ramesh, K.J. Hemker, Acta Mater., 46 (1998), 1025-1043.

[15] L. Wang, R.I. Barabash, Y. Yang, T.R. Bieler, M.A. Crimp, P. Eisenlohr, W. Liu, G.E. Ice, $\alpha$-Ti, Metall. Mater. Trans. A, 42 (2011), 626-635.

[16] J.L.W. Warwick, N.G. Jones, K.M. Rahman, D. Dye, Acta Mater., 60 (2012), $6720-6731$.

[17] M.H. Yoo, Metall. Trans. A, 12 (1981), 409-418.

[18] H. Numakura, Y. Minonishi, M. Koiwa, Scripta Metall., 20 (1986), 1581-1586. 
[19] N.E. Paton, W.A. Backofen, Metall. Trans., 1 (1970), 2839-2847.

[20] J.C. Williams, M.J. Blackburn, Physica Status Solidi 25 (1968), K1-K3.

[21] T. Sakai, M.E. Fine, Scripta Metall., 8 (1974), 541-544.

[22] T.R. Cass, The science, technology and application of titanium, Pergamon Press, New York, (1970), 459-477.

[23] Y.B. Chun, S.H. Yu, S.L. Semiatin, S.K. Hwang, Mater. Sci. Eng. A, 398 (2005), 209-219.

[24] Y. Murayama, K. Obara, K. Ikeda, Trans. Japan Inst. Metals, 28 (1987), 564-578.

[25] J.W. Christian, S. Mahajan, Progress in Mater. Sci., 39 (1995), 1-157.

[26] N. Stanford, U. Carlson, M.R. Barnett, Metall. Mater. Trans. A, 39 (2008), 934-944.

[27] A. Ghaderi, M.R. Barnett, Acta Mater., 59 (2011), 7824-7839.

[28] N. Bozzolo, L. Chan, A.D. Rollett, J. Appl. Crystallogr., 43 (2010), 596-602.

[29] W. Tirry, S. Bouvier, N. Benmhenni, W. Hammami, A.M. Habraken, F. Coghe, D. Schryvers, L. Rabet, Mater. Characterization, 72 (2012), 24-36.

[30] X.G. Deng, S.X. Hui, W.J. Ye, X.Y. Song, Mater. Sci. Eng. A, 575 (2013), 15-20.

[31] L. Wang, R. Barabash, T. Bieler, W. Liu, Metall. Mater. Trans. A, 44 (2013), 3664-3674. 
[32] H. Becker, W. Pantleon, Comput. Mater. Sci., 76 (2013), 52-59.

[33] X.Y. Lou, M. Li, R.K. Boger, S.R. Agnew, R.H. Wagoner, Int. J. Plasticity, 23 (2007), 44-86.

[34] T. Hama, Y. Kariyazaki, N. Hosokawa, H. Fujimoto, H. Takuda, Mater. Sci. Eng. A, 551 (2012), 209-217.

[35] T. Hama, H. Nagao, Y. Kuchinomachi, H. Takuda, Mater. Sci. Eng. A, 591(2014), 69-77.

[36] C.H. Cáceres, T. Sumitomo, M. Veidt, Acta Mater., 51 (2003), 6211-6218.

[37] Y.N. Wang, J.C. Huang, Acta Mater., 55 (2007), 897-905.

[38] L. Wu, S.R. Agnew, D.W. Brown, G.M. Stoica, B. Clausen, A. Jain, D.E. Fielden, P.K. Liaw, Acta Mater., 56 (2008), 3699-3707.

[39] Y. Li, M. Enoki, Mater. Trans., 49 (2008), 1800-1805.

[40] S.M. Yin, H.J. Yang, S.X. Li, S.D. Wu, F. Yang, Scripta Mater., 58 (2008), 751-754.

[41] O. Muránsky, D.G. Carr, P. Sittner, E.C. Oliver, Int. J. Plasticity, 25 (2009), 1107-1127.

[42] Q. Yu, J. Zhang, Y. Jiang, Philosophical Magazine Letters, 91 (2011), 757-765.

[43] J. Zhang, Q. Yu, Y. Jiang, Q. Li, Int. J. Plasticity, 27 (2011), 768-787. 
[44] T. Hama, and H. Takuda, Steel Res. Int., Special Issue Metal forming (2012), $1115-1118$.

[45] T. Hama, N. Kitamura, H. Takuda, Mater. Sci. Eng. A, 583 (2013), 232-241.

[46] H. Wang, P.D. Wu, J. Wang, Int. J. Plasticity, 47 (2013), 49-64.

[47] H. Wang, P.D. Wu, J. Wang, C.N. Tome, Int. J. Plasticity, 49 (2013), 36-52.

[48] L. Qu, Y. Yang, Y.F. Lu, L. Feng, J.H. Ju, P. Ge, W. Zhou, D. Han, D.H. Ping, Scripta Mater., 69 (2013), 389-392.

[49] J. Huang, Z. Wang, and J. Zhou, Metall. Mater. Trans. A, 42(2011), 2868-2880.

[50] N. Shamsaei, M. Gladskyi, K. Panasovskyi, S. Shukaev, A. Fatemi, Int. J. Fatigue, 32 (2010), 1862-1874.

[51] J. Peng, C-Y. Zhou, Q. Dai, X-H. He, X. Yu, Mater. Sci. Eng. A., 590 (2014), $329-337$

[52] M. Tritschler, A. Butz, D. Helm, G. Falkinger, J. Kiese, Int. J. Mater. Form., 7 (2014), 259-273.

[53] T. Kuwabara, Y. Kumano, J. Ziegelheim, I. Kurosaki, Int. J. Plasticity, 25 (2009), $1759-1776$.

[54] T. Hama, N. Kitamura, K. Ochi, H. Fujimoto, H. Takuda, Steel Res. Int., Special edition, (2011), 1054-1059. 
[55] U.F. Kocks, H. Mecking, Progress in Mater. Sci., 48 (2003), 171-273.

[56] F. Yoshida, T. Uemori, Int. J. Plasticity, 18 (2002), 661-686.

[57] Y. Sunaga, Y. Tanaka, M. Asakawa, M. Katoh, M. Kobayashi, J. Japan Inst. Light Metals, 59 (2009), 655-658 (in Japanese).

[58] N. Benmhenni, S. Bouvier, R. Brenner, T. Chauveau, B. Bacroix, Mater. Sci. Eng. A, 573 (2013), 222-233.

[59] M. Knezevic, R. A. Lebensohn, O. Cazacu, B. Revil-Baudard, G. Proust, S.C.

Vogel, M.E. Nixon, Mater. Sci. Eng. A, 564 (2013), 116-126.

[60] A. A. Salem, S.R. Kalidindi, R.D. Doherty, Acta Mater., 51 (2003), 4225-4237.

[61] H. Sasano, H. Kimura, J. Japan Inst. Metals and Materials, 41 (1977), 933-939 (in Japanese).

[62] A. Roth, M.A. Lebyodkin, T.A. Lebedkina, J.-S. Lecomte, T. Richeton, K.E.K. Amouzou, Mater. Sci. Eng. A, 596 (2014), 236-343.

Figure captions

Fig. 1. Geometry of a specimen used in the experiment with measurements expressed in $\mathrm{mm}$.

Fig. 2. Schematic diagrams of the experimental apparatus. (a) The entire 
experimental setup is detailed and (b) a magnified view of the comb-shaped dies.

Fig. 3. True stress-logarithmic strain curves obtained under monotonic tension and monotonic compression for the rolling direction (RD) and transverse direction (TD) samples. The stress and the strain are in absolute values.

Fig. 4. Variations of the work-hardening rate as a function of stress during monotonic tension and monotonic compression for the rolling direction (RD) and the transverse direction (TD) samples.

Fig. 5. True stress-logarithmic strain curves obtained under reverse loading for the rolling direction (RD) and the transverse direction (TD) samples. The magnitude of strain imparted before the loading direction was inverted was approximately 0.05 . (a) Compression-tension (CT), (b) tension-compression (TC), and (c) both results where signs of stress and strain for tension-compression were inverted.

Fig. 6. Variations of work-hardening rate as a function of stress during reverse loading. The magnitude of strain imparted before the loading direction was inverted was approximately 0.05 . The results after the loading direction was inverted are shown. RD $=$ rolling direction; $\mathrm{TD}=$ transverse direction; $\mathrm{CT}=$ compression-tension $; \mathrm{TC}=$ tension-compression.

Fig. 7. Evolutions of Lankford value as a function of strain obtained under 
monotonic tension. $\mathrm{RD}=$ rolled direction; $\mathrm{TD}=$ transverse direction.

Fig. 8. True stress-logarithmic strain curves obtained under reverse loading with various pre-strains for the rolling direction (RD) sample. (a) Compression-tension (CT), (b) tension-compression (TC), and (c) both results where signs of stress and strain were inverted for tension-compression.

Fig. 9. (0001) and ( $\left.\begin{array}{llll}1 & 0 & \overline{1} & 0\end{array}\right)$ pole figures for the rolling direction (RD) sample. Results are at (a) point $\mathrm{O}$, (b) point $\mathrm{A}$, (c) point $\mathrm{B}$, (d) point $\mathrm{C}$, and (e) point $\mathrm{D}$ shown in Figs. 8 (a) and 8 (b).

Fig. 10. Inverse pole figures and extracted twin boundaries for the rolling direction (RD) sample. Results are at (a) point $\mathrm{O}$, (b) point $\mathrm{A}$, (c) point $\mathrm{B}$, (d) point $\mathrm{C}$, and (e) point $\mathrm{D}$ shown in Figs. 8 (a) and 8 (b). TD = transverse direction.

Fig. 11. Results of microstructure observation at point B (Fig. 8 (b)) for the transverse direction (TD) sample. (a) Pole figures, and (b) inverse pole figures and extracted twin boundaries. $\mathrm{RD}=$ rolling direction . 


\section{Work-Hardening and Twinning Behaviors in a Commercially Pure Titanium Sheet under Various Loading Paths}

Takayuki HAMA*

Hirotaka NAGAO

Akihiro KOBUKI

Hitoshi FUJIMOTO

Hirohiko TAKUDA

Department of Energy Science and Technology, Kyoto University, Yoshida-honmachi,

Sakyo-ku, Kyoto 606-8501, Japan

Keywords: Commercially pure titanium sheet

Hexagonal close-packed structure

Work-hardening

Bauschinger effect

Twinning

Detwinning 
Corresponding author: Takayuki HAMA

Department of Energy Science and Technology, Kyoto University

Yoshida-Honmachi, Sakyo-ku, Kyoto 606-8501, Japan

TEL: $\quad+81-(0) 75-753-5418$

FAX: $\quad+81-(0) 75-753-5428$

E-mail: $\quad \underline{\text { hama@energy.kyoto-u.ac.jp }}$

\section{Abstract}

In this study, the work-hardening and twinning behaviors in a commercially pure titanium sheet were examined under various loading paths including reverse loading. The yield stress was identical between tension and compression, while the work-hardening was slightly larger during compression than during tension. These tendencies were the same in both the rolling and transverse directions. When the sheet was subjected to reverse loading, the Bauschinger effect was observed during both tension-compression and compression-tension. The tendency in the Bauschinger effect was nearly independent of the strain path tested in the present study. Concerning the twinning, the activities of $\{10 \overline{1} 2\}$ tensile twinning, $\{11 \overline{2} 2\}$ compressive twinning, and 
$\{11 \overline{2} 1\}$ tensile twinning were observed during tension. Alternatively, during compression, the activity of $\{10 \overline{1} 2\}$ tensile twinning was observed and was much larger than that during tension. When the sheet was subjected to tension following compression, detwinning occurred. Although the trend in the activity of twinning was similar to that of a magnesium alloy sheet, the behavior observed in the stress-strain curves was quite different from that of a magnesium alloy sheet. Based on the results presented, the effect of twinning and detwinning activities on the work-hardening behavior was discussed. 


\section{Introduction}

With properties such as low density, high corrosion resistance, and high heat resistance, commercially pure titanium (hereafter referred to as $\mathrm{CP}-\mathrm{Ti}$ ) is widely used in various applications such as chemical plants, heat exchangers, and chassis of mobile phone and computer [1-3]. CP-Ti sheets have high ductility at room temperature, therefore they are often manufactured at room temperature by press forming and bending.

Alternatively, it is also well known that rolled CP-Ti sheets demonstrate strong anisotropic deformation behavior. For instance, their Lankford value ( $r$-value), i.e., the ratio between the width and thickness strains, is very high and it differs notably between the rolling direction (RD) and the transverse direction (TD) [2-4]. In addition, the work-hardening behavior exhibited by rolled CP-Ti sheets differs between tension and compression [3-7] as well as between the RD and the TD [3,4,6,8,9]. Among the previous examples, the high $r$-value is advantageous for press forming because this yields good deep drawability. Alternatively, because of the strong anisotropy observed between tension and compression and between the RD and the TD, it is recognized that press forming of CP-Ti sheets is quite difficult.

The strong anisotropy in CP-Ti sheets is because of the strong crystal anisotropy of 
the hexagonal close-packed (hereafter referred to as hcp) structure and the strong basal texture with $c$-axes tilted between $20^{\circ}$ to $40^{\circ}$ from the normal direction (ND) to the TD $[2,3,6,7,9,10]$. In CP-Ti sheets at room temperature, $\{10 \overline{1} 0\}<11 \overline{2} 0>$ prismatic slip is the easiest family to be activated, however $(0001)<11 \overline{2} 0>$ basal slip and $\{10 \overline{1} 1\}$ $<11 \overline{2} 0>$ pyramidal slip are also active [10-16]. Alternatively, because there are only four independent slip systems in the three previously mentioned families, at least one other independent deformation mode is necessary to satisfy the von Mises criterion [17]. From earlier studies, it is known that $\{10 \overline{1} 1\}<11 \overline{2} 3>$ pyramidal slip, $\{11 \overline{2} 2\}<11 \overline{2} 3\rangle$ pyramidal slip [18-22], or twinning [2, 9, 10, 19, 23, 24, 25] may act as the additional deformation mode.

In polycrystalline $\mathrm{CP}-\mathrm{Ti}$, the activity of several twin modes has been reported: $\{10 \overline{1} 2\},\{11 \overline{2} 1\}$, and $\{11 \overline{2} 3\}$ tensile twinning, and $\{11 \overline{2} 2\},\{10 \overline{1} 1\}$, and $\{11 \overline{2} 4\}$ compressive twinning $[9,10,19]$. Among them, at room temperature the activities of $\{10 \overline{1} 2\}$ tensile twinning and $\{11 \overline{2} 2\}$ compressive twinning are most common compared to the other twinning modes. Chun et al. [23] reported that $\{10 \overline{1} 1\}$ compressive twinning and $\{11 \overline{2} 1\}$ tensile twinning were difficult to activate because of a large shuffling parameter and high twinning shear strain, respectively. Paton et al. [19] also demonstrated that the activity of $\{10 \overline{1} 1\}$ compressive twinning was negligible at 
temperatures below $300^{\circ} \mathrm{C}$. Murayama et al. [24] concluded from their experiments that $\{10 \overline{1} 2\}$ tensile twinning and $\{11 \overline{2} 2\}$ compressive twinning were observed, whereas $\{11 \overline{2} 3\}$ tensile twinning and $\{11 \overline{2} 4\}$ compressive twinning were not observed under uniaxial tension at room temperature.

Mullins et al. [9] examined active twin modes during uniaxial, plane strain, and equibiaxial tension in a rolled $\mathrm{CP}-\mathrm{Ti}$ sheet. Under uniaxial tension along the RD, $\{11 \overline{2} 2\}$ compressive twinning and $\{11 \overline{2} 4\}$ compressive twinning were active, whereas under uniaxial tension along the TD $\{10 \overline{1} 2\}$ tensile twinning was also active. These results were similar to those reported by Ishiyama et al. [2]. The active twin modes under plane strain and equibiaxial tension were also similar to those of uniaxial tension; however, the volume fraction of twinned area was much larger than that of uniaxial tension. Stanford et al. [26] conducted a compression test in a wire-drawn CP-Ti sample and depicted that $\{10 \overline{1} 2\}$ tensile twinning was the most active twin mode and $\{11 \overline{2} 2\}$ compressive twinning and $\{11 \overline{2} 1\}$ tensile twinning were also active. They also reported that $\{11 \overline{2} 2\}$ compressive twinning was very sensitive to grain size. Ghaderi and Barnett [27] also examined the sensitivity of twinning to grain size in CP-Ti. Bozzolo et al. [28] observed misorientations induced by twinning during cold rolling in CP-Ti and showed that $\{11 \overline{2} 2\}$ compressive twinning was very active and $\{10 \overline{1} 2\}$ tensile twinning and 
$\{11 \overline{2} 1\}$ tensile twinning were also active. Tirry et al. [29] carried out a monotonic simple shear test in a CP-Ti plate and presented that $\{10 \overline{1} 2\}$ tensile twinning could be activated easier than $\{11 \overline{2} 2\}$ compressive twinning. Deng et al. [30] reported a similar result. Li et al. [31] investigated the activity of $\{11 \overline{2} 1\}$ tensile twinning under tension in a CP-Ti plate and reported that the activity of $\{11 \overline{2} 1\}$ tensile twinning was much less than that of $\{10 \overline{1} 2\}$ tensile twinning. Murasawa et al. [7] performed the uniaxial tensile test on a rolled $\mathrm{CP}-\mathrm{Ti}$ sheet and found that the twinning nucleated and grew around the yield point. This successive twin nucleation around the yield point was pronounced when the angle between the tensile and rolling direction was smaller than $30^{\circ}$. Becker et al. [32] examined the work-hardening behavior under tension in a rolled CP-Ti sheet. The authors identified three different work-hardening stages depending on the work-hardening rate and explained the dominant mechanism as follows. Plastic deformation was dominated primarily by prismatic and basal slip and additionally by pyramidal $\langle\mathrm{a}+\mathrm{c}\rangle$ slip in the first stage, whereas $\{11 \overline{2} 2\}$ compressive twinning and $\{10 \overline{1} 2\}$ tensile twinning were active in the second and third stages, respectively. Mullins et al. [9] also reported that twinning was active only at the latter stage of deformation under tension.

As described earlier, extensive studies have been conducted to identify the twinning 
activity in CP-Ti sheets. Considering strong basal texture is generally developed in CP-Ti sheets, the active twin mode may be different between tension and compression. However, to the best of our knowledge, the identification of the twinning activity has been done under either tension or compression but a comparison between tension and compression has not yet been examined. Ishiyama et al. [2] investigated the activity of twinning under uniaxial tension and compression in the RD in a polycrystalline $\mathrm{CP}-\mathrm{Ti}$ sheet theoretically. They depicted that $\{11 \overline{2} 2\}$ compressive twinning could be activated under tension, while $\{10 \overline{1} 2\}$ and $\{11 \overline{2} 1\}$ tensile twinning would be active under compression. However, their discussion was based only on the Schmid factor and was not verified experimentally.

In rolled magnesium (hereafter referred to as $\mathrm{Mg}$ ) alloy sheets that also have the hcp structure, it is well known that $\{10 \overline{1} 2\}$ tensile twinning is active when the sheet is subjected to in-plane compression. That twinning activation occurs because of the strong basal texture of the $\mathrm{Mg}$, however detwinning is easily activated when the loading direction is inverted to tension [33-43]. The activities of twinning and detwinning play important roles in deformation behavior such as work-hardening under reverse loading and the nonlinearity in the stress-strain curve during unloading; thus they have been investigated extensively both experimentally and theoretically [44-47]. Based on the 
large activity of twinning in CP-Ti sheets observed in the earlier parts of this study, it would be expected that the detwinning would also be active under reverse loading in CP-Ti sheets. Moreover, detwinning has been reported in Ti alloys with a body-centered cubic structure [48, 49]. However, to the best of our knowledge, studies on the deformation behavior upon strain path changes in CP-Ti sheets are scarce; hence, the activity of detwinning upon strain path changes has not been observed. Shamsaei et al. [50] and Peng et al. [51] performed fatigue tests in CP-Ti and examined the stress-strain behavior and the fatigue life in detail. Alternatively, the activity of twinning was not investigated in their studies. Tritschler et al. [52] conducted a cyclic loading test in a $\mathrm{Ti}$ alloy sheet with hcp structure and modeled the work-hardening behavior. However, microstructure upon cyclic loading was not observed; hence, the occurrence of detwinning and the effect of twinning activity on the work-hardening behavior upon cyclic loading are not yet understood. Because sheets are often subjected to reverse loading such as bending-unbending in press forming, it is worth examining the occurrence of detwinning and the deformation behavior of CP-Ti sheets upon strain path changes.

The present study investigates the work-hardening and twinning behaviors in a CP-Ti sheet under in-plane tension, compression, compression followed by tension 
(hereafter referred to as compression-tension), and tension followed by compression (hereafter referred to as tension-compression). In particular, the occurrence of detwinning upon reverse loading is examined carefully. To this end, the stress-strain curves and the microstructure evolution using electron backscatter diffraction (hereafter referred to as EBSD) are investigated in detail.

2. Experimental details

\subsection{Material}

A cold rolled CP-Ti sheet (Kobe Steel, JIS grade 2) with $1 \mathrm{~mm}$ thickness was used in the present study. A specimen shown in Fig.1 was machined parallel to the RD or the TD. A specimen cut parallel to the RD or the TD is hereafter referred to as the RD sample or the TD sample, respectively. The samples were annealed for approximately 1 hour at $530^{\circ} \mathrm{C}$ before testing. The average grain size was approximately $20 \mu \mathrm{m}$.

\subsection{Experimental procedure}

Testing was performed in in-plane monotonic tension, monotonic compression, compression-tension, and tension-compression. To prevent buckling during compression, comb-shaped dies were used during testing to provide a compressive force 
in the thickness direction of the sample [34, 35, 53]. Figure 2 depicts the schematic diagrams of the experimental apparatus and the comb-shaped dies. Mineral hydraulic oil with a nominal kinematic viscosity of $32 \mathrm{cSt}$ at $40^{\circ} \mathrm{C}$ was used to provide lubrication between the comb-shaped dies and the sample. A hydraulic pump delivered the compressive force in the thickness direction. The magnitude of the through-thickness stress was $9 \mathrm{MPa}$ or approximately $3 \%$ of the yield stress of the CP-Ti sheet. The magnitude of compressive force was determined to suppress buckling and to minimize the influence of friction between the dies and specimen as much as possible. Further, because it was difficult to optimize the lubrication condition between CP-Ti sheets and dies [2], the effect of friction on the stress-strain curve could not be removed completely in the present study. However, the qualitative tendency observed in the results remained unchanged irrespective of the variability in the friction condition; thus, it is still worthwhile to examine them.

The tests were conducted at an initial strain rate of $6.67 \times 10^{-4} / \mathrm{s}^{-1}$ at room temperature [34, 35, 54]. Longitudinal strains were measured using a strain gauge (Kyowa Electronic Instruments, KFEM series). It should be noted that after every strain of several percent, a new strain gauge replaced the one in use. This replacement was made because it was observed that the strain gauge could easily become detached from 
the CP-Ti sheet.

An evolution of $r$-value was also measured under tension to examine the plastic anisotropy of the material. The $r$-value was calculated in the form

$$
r=\frac{\varepsilon_{w}}{\varepsilon_{t}}=-\frac{\varepsilon_{w}}{\left(\varepsilon_{l}+\varepsilon_{w}\right)}
$$

where $\varepsilon_{l}, \varepsilon_{w}$, and $\varepsilon_{t}$ are the strains in the length, width, and thickness directions, respectively.

After the mechanical tests were conducted, the EBSD analysis was used to observe microstructures of the deformed specimens to investigate the activities of twinning and detwinning. The cross-sectional surface perpendicular to the loading direction of the deformed specimen was polished using a cross-section polisher. The EBSD analysis was performed with a step size of $1.0 \mu \mathrm{m}$ in all conditions. After EBSD patterns were measured, a pole figure and an inverse pole figure were analyzed using OIM-Analysis 7 (TSL Solutions). It should be noted that measured data whose confidence index was smaller than 0.1 was excluded before the measured result was analyzed.

3. Results and discussion

3.1 Stress-strain curves

In this section, the stress-strain curves under various loading paths are investigated. 
First, the results of the RD sample are described.

The stress-strain curves obtained from the monotonic tension and compression tests are shown in Fig. 3, wherein the true stress and logarithmic strain are expressed in absolute values. Because a new strain gauge replaced the one in use as described in section 2.2 , the sheets were once unloaded at strain of approximately 0.05 in all conditions. A comparison of the tension and compression curves reveals that the same yield stress is achieved under both conditions, whereas the work-hardening is slightly larger under compression than under tension. This result exhibits the asymmetry between tension and compression and is similar to another finding also reported in the literature [6].

A variation of work-hardening rate as a function of flow stress $[32,55]$ is used to investigate the work-hardening in detail. The work-hardening rate was calculated using two points for every five-hundred successive data points or a strain increment of approximately 0.003 . Figure 4 displays the results during tension and compression for the RD and the TD samples. It should be noted that only the results in the plastic deformation range are discussed. Under both tension and compression, the work-hardening rate decreases sharply at the beginning of plastic deformation and then the slopes flatten at moderate strains. A difference in the variations of the 
work-hardening rate obtained between tension and compression is very small as also observed in Fig. 4. Becker et al. [32] reported that three different stages could be distinguished in the variation of work-hardening rate; however, in Fig. 4 only two stages, i.e., the initial sharp decrease and the following gradual decrease, are observed. This difference from the result reported by Becker et al. may be because of the difference in the strain range examined. Becker et al. investigated the deformation until the necking arose, whereas in the present study the deformation up to an absolute strain of $10 \%$ was examined.

Figures 5 (a) and 5 (b) depict the stress-strain curves obtained under compression-tension and tension-compression, respectively. In both cases, the amount of strain imparted during the first loading was approximately 0.05. For direct comparison of the results between tension-compression and compression-tension, Fig. 5 (c) shows the results for cases where the signs of stress and strain for tension-compression were inverted. In the following figures, compression-tension and tension-compression are denoted by CT and TC, respectively. In both results, the yield stresses after the loading direction was inverted are much smaller than the flow stresses before the loading direction was inverted, thereby exhibiting a strong Bauschinger effect under both compression-tension and tension-compression. The stress-strain curves after 
the loading direction was inverted under tension-compression and compression-tension are very similar.

Figure 6 demonstrates the variation of the work-hardening rate during tension-compression and compression-tension after the loading direction was inverted.

In both conditions, the decrease in the work-hardening rate at the beginning of plastic deformation is more gradual than that observed under the monotonic loading paths (Fig. 4). Moreover, the two different stages in the slope observed in Fig. 4 are unclear. These differences between the monotonic loading and the reverse loading may be because of the Bauschinger effect.

Next, the results of the TD sample are described focusing on the difference from the results of the RD sample. Under monotonic tension (Fig.3), the yield stress is larger but the work-hardening is smaller in the TD sample than in the RD sample. Under compression, the yield stress in the TD sample is still larger than in the RD sample, whereas the work-hardening is similar to that in the RD sample. Comparing the results in the TD sample between tension and compression, the yield stress under compression is comparable to that under tension, whereas the work-hardening is larger under compression than under tension. The difference in the work-hardening can also be observed in the variation of the work-hardening rate (Fig. 4). 
When the sheet is subjected to the strain-path change, the Bauschinger effect also arises in the TD sample (Fig. 5). Therefore, the initial decrease in the work-hardening rate is more gradual than that under monotonic loading as in the case of the RD sample (Fig. 6). The flow stresses during tension-compression and compression-tension are slightly larger under the TD sample than under the RD sample. This result is consistent with that observed under monotonic loading (Fig. 3). Comparing the results in the TD sample between compression-tension and tension-compression (Fig. 5 (c)), the work-hardening after the loading direction was inverted is larger under tension-compression than under compression-tension. This trend is the same as that observed during monotonic loading shown in Fig. 3.

Fig. 7 shows the evolutions of $r$-value under tension. The $r$-value is notably larger for the TD sample than that of the RD sample. This tendency is consistent with the results reported in the literature [2-4].

The results obtained are summarized here. The CP-Ti sheet demonstrated small in-plane anisotropy under both tension and compression; however, the characteristics of the anisotropy differed between tension and compression. Such in-plane anisotropy of CP-Ti sheets has been reported in many studies $[3,4,6,8,9]$ although characteristics of anisotropy were somewhat different depending on materials used. It was also found 
that during reverse loading a strong Bauschinger effect occurred regardless of the conditions. Moreover, the work-hardening behavior after the loading direction was inverted tended to be similar to that of monotonic loading, indicating that the effect of reverse loading on the work-hardening behavior would be small except for the occurrence of the Bauschinger effect.

\subsection{The Bauschinger effect}

In this section, the Bauschinger effect observed in the CP-Ti sheet is examined more in detail. The results of the RD sample are used to examine the tendency.

Figure 8 (a) displays the stress-strain curves obtained under compression-tension with compressive strains of approximately $0.02,0.05$, and 0.1 . The result with a compressive strain of 0.05 is the same as that shown in Fig. 5. Early re-yielding and a transient Bauschinger effect [56] are observed irrespective of the amount of compressive strain, and the tendency in the transient Bauschinger effect seems to be similar regardless the amount of compressive strain. Fig. 8 (b) presents the results obtained under tension-compression with tensile strains of approximately $0.02,0.05$, and 0.1. It should be noted that the sheet was once unloaded for the replacement of the strain gauge in the test with tensile strain of approximately 0.1. Similar to 
compression-tension, early re-yielding and a transient Bauschinger effect are also exhibited under these conditions. The tendency observed under tension-compression is very similar to that of compression-tension. To examine this similarity in detail, Fig. 8 (c) shows the results for cases where the signs of stress and strain are inverted in the results of tension-compression. The stress-strain curves obtained under tension-compression are noticeably in good agreement with those of compression-tension except that the work-hardening is slightly larger under compression than tension. This result indicates that the tendency in the Bauschinger effect is almost independent of the sequence of tension and compression.

\subsection{Microstructural observation}

The results of the RD sample were used to examine the deformation behavior from a microscopic point of view using the EBSD analysis. The microstructures were observed after unloading at points $\mathrm{O}, \mathrm{A}, \mathrm{B}, \mathrm{C}$, and D as indicated in Figs. 8 (a) and 8 (b). The pole figures and the inverse pole figures at these points are shown in Figs. 9 and 10, respectively. To investigate the activity of twinning, the figures where only twin boundaries were extracted from the inverse pole figure maps are also shown in Fig. 10. The extracted twinning systems are $\left\{\begin{array}{lllll}1 & 0 & \overline{1} & 2\end{array}\right\}$ and $\left\{\begin{array}{lllll}1 & 1 & \overline{2} & 1\end{array}\right\}$ tensile twinning and 
$\{11 \overline{2} 2\}$ compressive twinning. The other twin modes were rarely observed in this study. It should be noted that the dots observed on the maps are the result of noise; hence, they are neglected in the following discussion.

The initial microstructures (point O, Figs. 9 (a) and 10 (a)) are as follows. Two peaks tilted $20^{\circ}$ to $30^{\circ}$ from the ND to the TD are observed in the (0001) pole figure, while a strong peak is not observed in the $\left(\begin{array}{llll}1 & 0 & 1 & 0\end{array}\right)$ pole figure. The orientation of the $\left(\begin{array}{llll}1 & 0 & \overline{1} & 0\end{array}\right)$ direction is approximately perpendicular to the ND. These are the typical cold rolling texture of a CP-Ti sheet $[2,3,6,7,9,10]$. Twin boundaries are rarely observed in the inverse pole figure map, indicating that the twinning does not occur in the initial texture.

When tensile deformation was imparted from point $\mathrm{O}$ to point $\mathrm{A}$, the (0001) pole figure remained almost unchanged, whereas in the $\left(\begin{array}{llll}1 & 0 & \overline{1} & 0\end{array}\right)$ pole, relatively strong peaks tend to appear around the RD (Fig. 9 (b)). The presented results are consistent with those reported by Becker et al. [32]. As shown in Fig. 10 (b), the activities of $\left\{\begin{array}{llll}1 & 1 & \overline{2} & 2\end{array}\right\}$ compressive twinning and $\left\{\begin{array}{lllll}1 & 0 & \overline{1} & 2\end{array}\right\}$ tensile twinning are observed. To a more limited extent, $\left\{\begin{array}{llll}1 & 1 & \overline{2} & 1\end{array}\right\}$ tensile twinning is also observed. Among the twin modes, $\{11 \overline{2} 2\}$ compressive twinning seems to be the most active. This result is similar to those reported in the literature [9, 19, 23, 24]. 
When compressive deformation was applied from point $\mathrm{O}$ to point $\mathrm{B}$, two peaks appear around the $\mathrm{RD}$ in the (0001) pole figure, while six peaks tend to appear perpendicular to the ND in the $\left(\begin{array}{llll}1 & 0 & \overline{1} & 0\end{array}\right)$ pole figure (Fig. 9 (c)). Meanwhile,

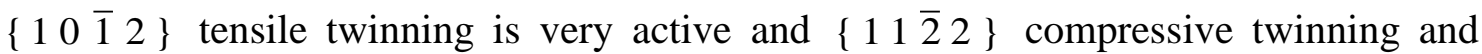
$\left\{\begin{array}{lll}1 & 1 & 2 \\ 1\end{array}\right\}$ tensile twinning are also observed to a small extent as shown in Fig. 10 (c). The lattice rotation induced by the activity of $\left\{\begin{array}{llll}1 & 0 & \overline{1} & 2\end{array}\right\}$ tensile twinning is approximately $84.8^{\circ}$, therefore the $c$-axes of grains, which are tilted $20^{\circ}$ to $30^{\circ}$ from the ND to the TD, would be rotated to the vicinity of the RD when $\left\{\begin{array}{llll}1 & 0 & \overline{1} & 2\end{array}\right\}$ tensile twinning is activated. Accordingly, the peaks observed around the RD in the (0001) pole figure at point $\mathrm{B}$ may be caused by the activity of $\left\{\begin{array}{llll}1 & 0 & \overline{1} & 2\end{array}\right\}$ tensile twinning. Warwick et al. [16] also reported a similar result.

As described in the previous results, the $\left\{\begin{array}{llll}1 & 1 & \overline{2} & 2\end{array}\right\}$ compressive twinning and the $\left\{\begin{array}{llll}1 & 0 & \overline{1} & 2\end{array}\right\}$ tensile twinning are the most active modes under tension (Fig. 10 (b)) and compression (Fig. 10 (c)), respectively. The active twinning mode in tension is notably different from that in compression. This result can be understood in that the stresses that act along the $c$-axes become negative and positive under tension and compression, respectively, because of the strong basal texture. Alternatively, the activity of $\left\{\begin{array}{llll}1 & 0 & \overline{1} & 2\end{array}\right\}$ tensile twinning under compression is notably larger than that of $\left\{\begin{array}{llll}1 & 1 & \overline{2} & 2\end{array}\right\}$ 
compressive twinning under tension. In the typical rolling texture shown in Fig. 9 (a), the Schmid factor for $\left\{\begin{array}{llll}1 & 1 & \overline{2} & 2\end{array}\right\}$ compressive twinning under tension may be higher than that of $\left\{\begin{array}{lllll}1 & 0 & \overline{1} & 2\end{array}\right\}$ tensile twinning under compression [2], and this result indicates that the critical resolved shear stress for $\left\{\begin{array}{llll}1 & 1 & \overline{2} & 2\end{array}\right\}$ compressive twinning would also be higher than that of $\left\{\begin{array}{lllll}1 & 0 & \overline{1} & 2\end{array}\right\}$ tensile twinning. Moreover, because the activity of

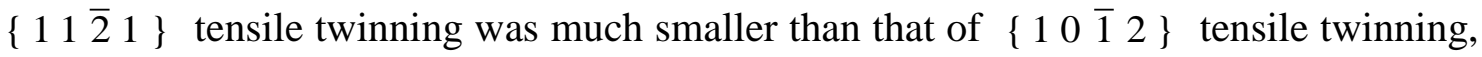
this result suggests that $\left\{\begin{array}{llll}1 & 0 & \overline{1} & 2\end{array}\right\}$ tensile twinning may be the most easily activated twinning mode in the examined CP-Ti sheet. These observations are consistent with observations reported in the literature [10,25].

When the sheet was subjected to tension following compression from point B to points $\mathrm{C}$ and $\mathrm{D}$, the two peaks observed around the $\mathrm{RD}$ in the (0001) pole figure during compression (Fig. 9 (c)) are not visible (Figs. 9 (d), and 9 (e)). At the same time, the number of the boundaries of the $\left\{\begin{array}{llll}1 & 0 & \overline{1} & 2\end{array}\right\}$ tensile twinning tends to decrease as the tensile strain increases (Figs. 10 (c), 10 (d), and 10 (e)). These tendencies observed in the pole figure and the twin boundaries are very similar to those observed in rolled $\mathrm{Mg}$ alloy sheets subjected to reverse loading [33-44], indicating that the $\left\{\begin{array}{lllll}1 & 0 & 1 & 2\end{array}\right\}$ detwinning is activated also in the CP-Ti sheet.

In the $\left(\begin{array}{llll}1 & 0 & \overline{1} & 0\end{array}\right)$ pole figures, six peaks observed during compression (Fig. 9 (c)) 
gradually become unclear as the tensile strain increases, and consequently, two peaks tend to arise around the RD (Figs. 9 (d) and 9 (e)). This tendency observed at point D is similar to those observed under monotonic tension (Fig. 9 (b)).

As described in the discussion of Figs. 9 and 10, the CP-Ti sheet showed the similar tendency with that of a rolled magnesium alloy sheet [33-44] where the $\left\{\begin{array}{lllll}1 & 0 & \overline{1} & 2\end{array}\right\}$ tensile twinning was active under in-plane compression and the detwinning was active when the sheet was subjected to reverse loading from compression to tension. Recently such twinning-detwinning characteristics are used to develop a magnesium alloy sheet with weak texture [57]. The contribution of a strong basal texture to the strong anisotropy observed in CP-Ti sheets $[2,3,6,7,9,10]$, along with the preceding results, suggests that a similar method may be applicable to develop a CP-Ti sheet with a weak texture.

3.4 Effect of twinning activity on the stress-strain curve

In a rolled magnesium alloy sheet, because the critical resolved shear stress of the $\left\{\begin{array}{llll}1 & 0 & \overline{1} & 2\end{array}\right\}$ tensile twinning is lower than that of nonbasal slip, the activities of twinning and detwinning considerably affect the stress-strain curve. For example, the yield stress under compression is smaller than that of tension, a plateau region with relatively low 
flow stress arises in the early stage of compression, and a sigmoidal curve occurs during tension following compression [33-44].

Alternatively, in the CP-Ti sheet the relationship between the twinning and detwinning activities and the work-hardening behavior seems to be different from that of a rolled magnesium alloy sheet. As explained in sections 3.1 and 3.3, the twinning activity is more pronounced under compression than under tension as in the case of a rolled magnesium alloy sheet, but at the same time the yield stress is almost the same between tension and compression and the work-hardening is slightly larger under compression than under tension. Moreover, the detwinning was observed when the sheet was subjected to compression-tension, but the stress-strain curve during tension following compression shows a monotonic increasing trend.

The detected differences in the effect of twinning and detwinning activities on the stress-strain curve between the CP-Ti sheet and a rolled magnesium alloy sheet may be related to the difference in the critical resolved shear stress of twinning. For Ti, it was reported that the critical resolved shear stress of twinning was larger than that of prismatic and basal slip [16, 58, 59]. Therefore, unlike in a rolled magnesium alloy sheet, the twinning experience in a $\mathrm{Ti}$ sheet tended to be active in the latter stage of deformation and larger work-hardening could be attained when the twinning was 
activated $[8,24,60,61]$. In fact, the prior observation reported in the literature is consistent with the present results in which the work-hardening is slightly larger under compression than under tension.

Additionally, the difference in the critical resolved shear stress of twinning may also yield the difference in the magnitude of the twinning activity between the CP-Ti and magnesium alloy sheets. Comparison of the pole figures after the sheets of CP-Ti (Fig. 9 (c)) and rolled magnesium alloy [33] were subjected to compression reveals that twinning activity is smaller in the CP-Ti than in the magnesium alloy. The smaller activity of twinning in the $\mathrm{CP}-\mathrm{Ti}$ sheet could cause the effect of twinning and detwinning activities on the stress-strain curve to be smaller than that of the magnesium alloy sheet. This premise is supported by the fact that in CP-Ti the amount of plastic deformation contributed by twinning is much smaller than that by the activity of slip systems as reported in the literature $[13,14]$. The previous presumption is also consistent with the results that the difference in the work-hardening between tension and compression was small and that a significant difference was not observed in the stress-strain curves between compression-tension and tension-compression (Fig. 8 (c)) although the twinning and detwinning activities were notably different between tension and compression. The latter result further suggests that the effect of detwinning on the 
stress-strain curve may be negligible within the experimental conditions tested in the present study.

If the proposed mechanisms are valid, the twinning activity under compression may also be large in the TD sample because the work-hardening under compression was large as well as in the RD sample (Fig. 3). To examine this premise, the microstructures were observed after the TD sample was compressed to a strain of about -0.1 , which corresponds to point B in Fig. 8 (a). The results are shown in Fig. 11. The twinning activity was notably much smaller than that in the RD sample (Figs. 9 (c) and 10 (c)). Indeed, the difference in the twinning activity between the RD and the TD samples observed in the present study is consistent with an analysis using Schmid factor reported by Ishiyama et al. [2]. In that study, the authors suggested that theoretically, the activity of $\left\{\begin{array}{llll}1 & 0 & \overline{1} & 2\end{array}\right\}$ tensile twinning under compression might be much smaller in the TD sample than in the RD sample. This observation aligns well with those of other researchers and indicates that the large work-hardening attained under compression in both the RD and the TD samples would be attributable not only to the twinning activity but also to other factors $[13,62]$. Roth et al. [62] recently presumed that the difference in the work-hardening between the RD and the TD might be explained by the slip activity. A similar discussion may be applicable to explain the difference between 
tension and compression. Further investigation is necessary to understand the effect of twinning activity on the stress-strain curve in detail.

\section{Conclusion}

In the present study, the deformation behavior in a commercially pure titanium sheet was examined under monotonic tension, monotonic compression, tension followed by compression, and compression followed by tension. The stress-strain curves and the microstructure observation using EBSD analysis were used to investigate the work-hardening and twinning behaviors under the aforementioned conditions. Specimens cut parallel to the rolling direction were primarily used. The following conclusions were obtained:

(1) The yield stress is nearly the same in both tension and compression, while the work-hardening is slightly larger during compression than tension. When the sheet is subjected to reverse loading, early re-yielding and a transient Bauschinger effect are exhibited both during tension following compression and compression following tension. In this study, the tendency of the stress-strain curve upon reverse loading is almost independent of the sequence of tension and compression.

(2) The activities of the $\left\{\begin{array}{llll}1 & 0 & \overline{1} & 2\end{array}\right\}$ tensile twinning, $\left\{\begin{array}{lll}1 & 1 & \overline{2} \\ 2\end{array}\right\}$ compressive 
twinning, and $\left\{\begin{array}{llll}1 & 1 & \overline{2} & 1\end{array}\right\}$ tensile twinning are observed during tension. Alternatively, during compression, the activity of $\left\{\begin{array}{llll}1 & 0 & \overline{1} & 2\end{array}\right\}$ tensile twinning is observed and it is much larger than that during tension. These results demonstrate that the active twin modes and their activities are different between tension and compression. When the sheet is subjected to tension following compression, $\left\{\begin{array}{llll}1 & 0 & \overline{1} & 2\end{array}\right\}$ detwinning is observed.

(3) The tendency that the $\left\{\begin{array}{llll}1 & 0 & \overline{1} & 2\end{array}\right\}$ twinning and detwinning are active during compression and tension following compression, respectively, is similar to that of a magnesium alloy sheet that has the hexagonal close-packed structure as well as the commercially pure titanium sheet. Alternatively, the effect of twinning and detwinning activities on the work-hardening behavior would be significantly different from that of the magnesium alloy sheet. One of the reasons for this difference may be that the critical resolved shear stress is larger in the titanium sheet than the magnesium alloy sheet. This eventually leads to the trend that the activities of twinning and detwinning are smaller in the titanium sheet than that in the magnesium alloy sheet.

(4) When the sheet is subjected to compression in the transverse direction, the work-hardening is slightly larger than that under tension as in the case of the deformation in the rolling direction. Conversely, the activity of twinning is much 
smaller in the transverse direction than that in the rolling direction. This result indicates that the slightly larger work-hardening observed under compression rather than tension is attributable not only to twinning activity but also to other factors. This finding will be investigated in our future work.

\section{Acknowledgements}

The authors wish to acknowledge Dr. Tsutomu Tanaka and Dr. Takashi Nishimura of Technology Research Institute of Osaka Prefecture for their help with the EBSD analysis. This work was partially supported by JSPS KAKENHI Grant Number 26289271 and the Photon and Quantum Basic Research Coordinated Development Program from the Ministry of Education, Culture, Sports, Science and Technology, Japan.

References

[1] M. Usuda, M. Ishii, Titanium Japan, 52 (2004), 110-116 (in Japanese).

[2] S. Ishiyama, Titanium Japan, 54 (2006), $42-51$ (in Japanese).

[3] M. Ishiki, T. Kuwabara, Y. Hayashida, Int. J. Mater. Form., 4 (2011), 193-204.

[4] T. Kuwabara, C. Katami, M. Kikuchi, T. Shindo, T. Ohwue, Proc. NUMIFORM 
2001 (2001), 781-787.

[5] D. Lee, W.A. Backofen, Trans. Metall. Soc. AIME, 236 (1966), 1077-1084.

[6] M.E. Nixon, O. Cazacu, R.A. Lebensohn, Int. J. Plasticity, 26 (2010), 516-532.

[7] G. Murasawa, T. Morimoto, S. Yoneyama, Exp. Mech., 52 (2012), 503-512.

[8] M. Ogaya, M. Kisaichi, S. Ishiyama, Tetsu-to-Hagane, 72 (1986), 649-656 (in Japanese).

[9] S. Mullins, B.M. Patchett, Metall. Trans. A, 12 (1981), 853-863.

[10] H. Conrad, Progress in Mater. Sci., 26 (1981), 123-403.

[11] F.D. Rosi, C.A. Dube, B.H. Alexander, J. Metals, 5 (1953), 257-265.

[12] E.A. Anderson, D.C. Jillson, S.R. Dunbar, J. Metals, 5 (1953), 1191-1197.

[13] S. Nemat-Nasser, W.G. Guo, J.Y. Cheng, Acta Mater., 47 (1999), 3705-3720.

[14] D.R. Chichili, K.T. Ramesh, K.J. Hemker, Acta Mater., 46 (1998), 1025-1043.

[15] L. Wang, R.I. Barabash, Y. Yang, T.R. Bieler, M.A. Crimp, P. Eisenlohr, W. Liu, G.E. Ice, $\alpha$-Ti, Metall. Mater. Trans. A, 42 (2011), 626-635.

[16] J.L.W. Warwick, N.G. Jones, K.M. Rahman, D. Dye, Acta Mater., 60 (2012), $6720-6731$.

[17] M.H. Yoo, Metall. Trans. A, 12 (1981), 409-418.

[18] H. Numakura, Y. Minonishi, M. Koiwa, Scripta Metall., 20 (1986), 1581-1586. 
[19] N.E. Paton, W.A. Backofen, Metall. Trans., 1 (1970), 2839-2847.

[20] J.C. Williams, M.J. Blackburn, Physica Status Solidi 25 (1968), K1-K3.

[21] T. Sakai, M.E. Fine, Scripta Metall., 8 (1974), 541-544.

[22] T.R. Cass, The science, technology and application of titanium, Pergamon Press, New York, (1970), 459-477.

[23] Y.B. Chun, S.H. Yu, S.L. Semiatin, S.K. Hwang, Mater. Sci. Eng. A, 398 (2005), 209-219.

[24] Y. Murayama, K. Obara, K. Ikeda, Trans. Japan Inst. Metals, 28 (1987), 564-578.

[25] J.W. Christian, S. Mahajan, Progress in Mater. Sci., 39 (1995), 1-157.

[26] N. Stanford, U. Carlson, M.R. Barnett, Metall. Mater. Trans. A, 39 (2008), 934-944.

[27] A. Ghaderi, M.R. Barnett, Acta Mater., 59 (2011), 7824-7839.

[28] N. Bozzolo, L. Chan, A.D. Rollett, J. Appl. Crystallogr., 43 (2010), 596-602.

[29] W. Tirry, S. Bouvier, N. Benmhenni, W. Hammami, A.M. Habraken, F. Coghe, D. Schryvers, L. Rabet, Mater. Characterization, 72 (2012), 24-36.

[30] X.G. Deng, S.X. Hui, W.J. Ye, X.Y. Song, Mater. Sci. Eng. A, 575 (2013), 15-20.

[31] L. Wang, R. Barabash, T. Bieler, W. Liu, Metall. Mater. Trans. A, 44 (2013), 3664-3674. 
[32] H. Becker, W. Pantleon, Comput. Mater. Sci., 76 (2013), 52-59.

[33] X.Y. Lou, M. Li, R.K. Boger, S.R. Agnew, R.H. Wagoner, Int. J. Plasticity, 23 (2007), 44-86.

[34] T. Hama, Y. Kariyazaki, N. Hosokawa, H. Fujimoto, H. Takuda, Mater. Sci. Eng. A, 551 (2012), 209-217.

[35] T. Hama, H. Nagao, Y. Kuchinomachi, H. Takuda, Mater. Sci. Eng. A, 591(2014), 69-77.

[36] C.H. Cáceres, T. Sumitomo, M. Veidt, Acta Mater., 51 (2003), 6211-6218.

[37] Y.N. Wang, J.C. Huang, Acta Mater., 55 (2007), 897-905.

[38] L. Wu, S.R. Agnew, D.W. Brown, G.M. Stoica, B. Clausen, A. Jain, D.E. Fielden, P.K. Liaw, Acta Mater., 56 (2008), 3699-3707.

[39] Y. Li, M. Enoki, Mater. Trans., 49 (2008), 1800-1805.

[40] S.M. Yin, H.J. Yang, S.X. Li, S.D. Wu, F. Yang, Scripta Mater., 58 (2008), $751-754$

[41] O. Muránsky, D.G. Carr, P. Sittner, E.C. Oliver, Int. J. Plasticity, 25 (2009), 1107-1127.

[42] Q. Yu, J. Zhang, Y. Jiang, Philosophical Magazine Letters, 91 (2011), 757-765.

[43] J. Zhang, Q. Yu, Y. Jiang, Q. Li, Int. J. Plasticity, 27 (2011), 768-787. 
[44] T. Hama, and H. Takuda, Steel Res. Int., Special Issue Metal forming (2012), $1115-1118$.

[45] T. Hama, N. Kitamura, H. Takuda, Mater. Sci. Eng. A, 583 (2013), 232-241.

[46] H. Wang, P.D. Wu, J. Wang, Int. J. Plasticity, 47 (2013), 49-64.

[47] H. Wang, P.D. Wu, J. Wang, C.N. Tome, Int. J. Plasticity, 49 (2013), 36-52.

[48] L. Qu, Y. Yang, Y.F. Lu, L. Feng, J.H. Ju, P. Ge, W. Zhou, D. Han, D.H. Ping, Scripta Mater., 69 (2013), 389-392.

[49] J. Huang, Z. Wang, and J. Zhou, Metall. Mater. Trans. A, 42(2011), 2868-2880.

[50] N. Shamsaei, M. Gladskyi, K. Panasovskyi, S. Shukaev, A. Fatemi, Int. J. Fatigue, 32 (2010), 1862-1874.

[51] J. Peng, C-Y. Zhou, Q. Dai, X-H. He, X. Yu, Mater. Sci. Eng. A., 590 (2014), 329-337.

[52] M. Tritschler, A. Butz, D. Helm, G. Falkinger, J. Kiese, Int. J. Mater. Form., 7 (2014), 259-273.

[53] T. Kuwabara, Y. Kumano, J. Ziegelheim, I. Kurosaki, Int. J. Plasticity, 25 (2009), $1759-1776$.

[54] T. Hama, N. Kitamura, K. Ochi, H. Fujimoto, H. Takuda, Steel Res. Int., Special edition, (2011), 1054-1059. 
[55] U.F. Kocks, H. Mecking, Progress in Mater. Sci., 48 (2003), 171-273.

[56] F. Yoshida, T. Uemori, Int. J. Plasticity, 18 (2002), 661-686.

[57] Y. Sunaga, Y. Tanaka, M. Asakawa, M. Katoh, M. Kobayashi, J. Japan Inst. Light Metals, 59 (2009), 655-658 (in Japanese).

[58] N. Benmhenni, S. Bouvier, R. Brenner, T. Chauveau, B. Bacroix, Mater. Sci. Eng. A, 573 (2013), 222-233.

[59] M. Knezevic, R. A. Lebensohn, O. Cazacu, B. Revil-Baudard, G. Proust, S.C.

Vogel, M.E. Nixon, Mater. Sci. Eng. A, 564 (2013), 116-126.

[60] A. A. Salem, S.R. Kalidindi, R.D. Doherty, Acta Mater., 51 (2003), 4225-4237.

[61] H. Sasano, H. Kimura, J. Japan Inst. Metals and Materials, 41 (1977), 933-939 (in Japanese).

[62] A. Roth, M.A. Lebyodkin, T.A. Lebedkina, J.-S. Lecomte, T. Richeton, K.E.K. Amouzou, Mater. Sci. Eng. A, 596 (2014), 236-343.

Figure captions

Fig. 1. Geometry of a specimen used in the experiment with measurements expressed in $\mathrm{mm}$.

Fig. 2. Schematic diagrams of the experimental apparatus. (a) The entire 
experimental setup is detailed and (b) a magnified view of the comb-shaped dies.

Fig. 3. True stress-logarithmic strain curves obtained under monotonic tension and monotonic compression for the rolling direction (RD) and transverse direction (TD) samples. The stress and the strain are in absolute values.

Fig. 4. Variations of the work-hardening rate as a function of stress during monotonic tension and monotonic compression for the rolling direction (RD) and the transverse direction (TD) samples.

Fig. 5. True stress-logarithmic strain curves obtained under reverse loading for the rolling direction (RD) and the transverse direction (TD) samples. The magnitude of strain imparted before the loading direction was inverted was approximately 0.05 . (a) Compression-tension (CT), (b) tension-compression (TC), and (c) both results where signs of stress and strain for tension-compression were inverted.

Fig. 6. Variations of work-hardening rate as a function of stress during reverse loading. The magnitude of strain imparted before the loading direction was inverted was approximately 0.05 . The results after the loading direction was inverted are shown. RD $=$ rolling direction; $\mathrm{TD}=$ transverse direction; $\mathrm{CT}=$ compression-tension $; \mathrm{TC}=$ tension-compression.

Fig. 7. Evolutions of Lankford value as a function of strain obtained under 
monotonic tension. $\mathrm{RD}=$ rolled direction; $\mathrm{TD}=$ transverse direction.

Fig. 8. True stress-logarithmic strain curves obtained under reverse loading with various pre-strains for the rolling direction (RD) sample. (a) Compression-tension (CT), (b) tension-compression (TC), and (c) both results where signs of stress and strain were inverted for tension-compression.

Fig. 9. (0001) and ( $\left.\begin{array}{llll}1 & 0 & \overline{1} & 0\end{array}\right)$ pole figures for the rolling direction (RD) sample. Results are at (a) point $\mathrm{O}$, (b) point $\mathrm{A}$, (c) point $\mathrm{B}$, (d) point $\mathrm{C}$, and (e) point $\mathrm{D}$ shown in Figs. 8 (a) and 8 (b).

Fig. 10. Inverse pole figures and extracted twin boundaries for the rolling direction (RD) sample. Results are at (a) point $\mathrm{O}$, (b) point $\mathrm{A}$, (c) point $\mathrm{B}$, (d) point $\mathrm{C}$, and (e) point $\mathrm{D}$ shown in Figs. 8 (a) and 8 (b). TD = transverse direction.

Fig. 11. Results of microstructure observation at point B (Fig. 8 (b)) for the transverse direction (TD) sample. (a) Pole figures, and (b) inverse pole figures and extracted twin boundaries. $\mathrm{RD}=$ rolling direction . 


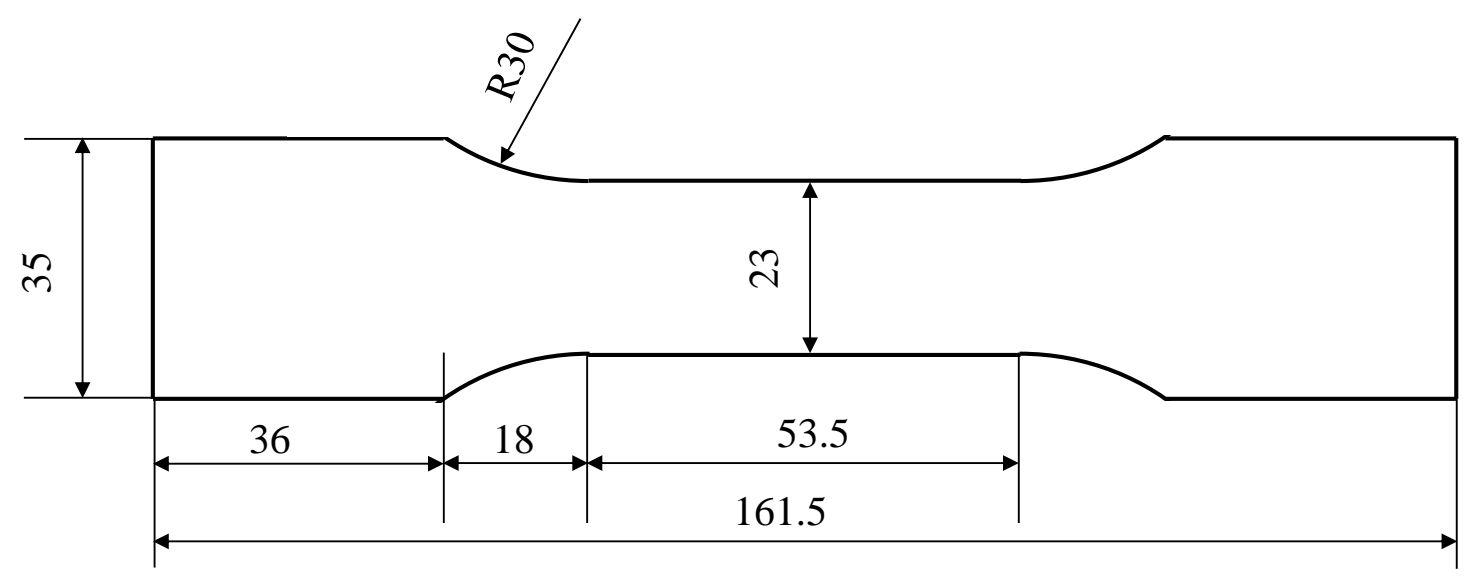

Fig. 1. Geometry of a specimen used in the experiment with measurements expressed in $\mathrm{mm}$. 


\section{(a) Screw nuts Hydraulic pump Pressure plates}

Specimen

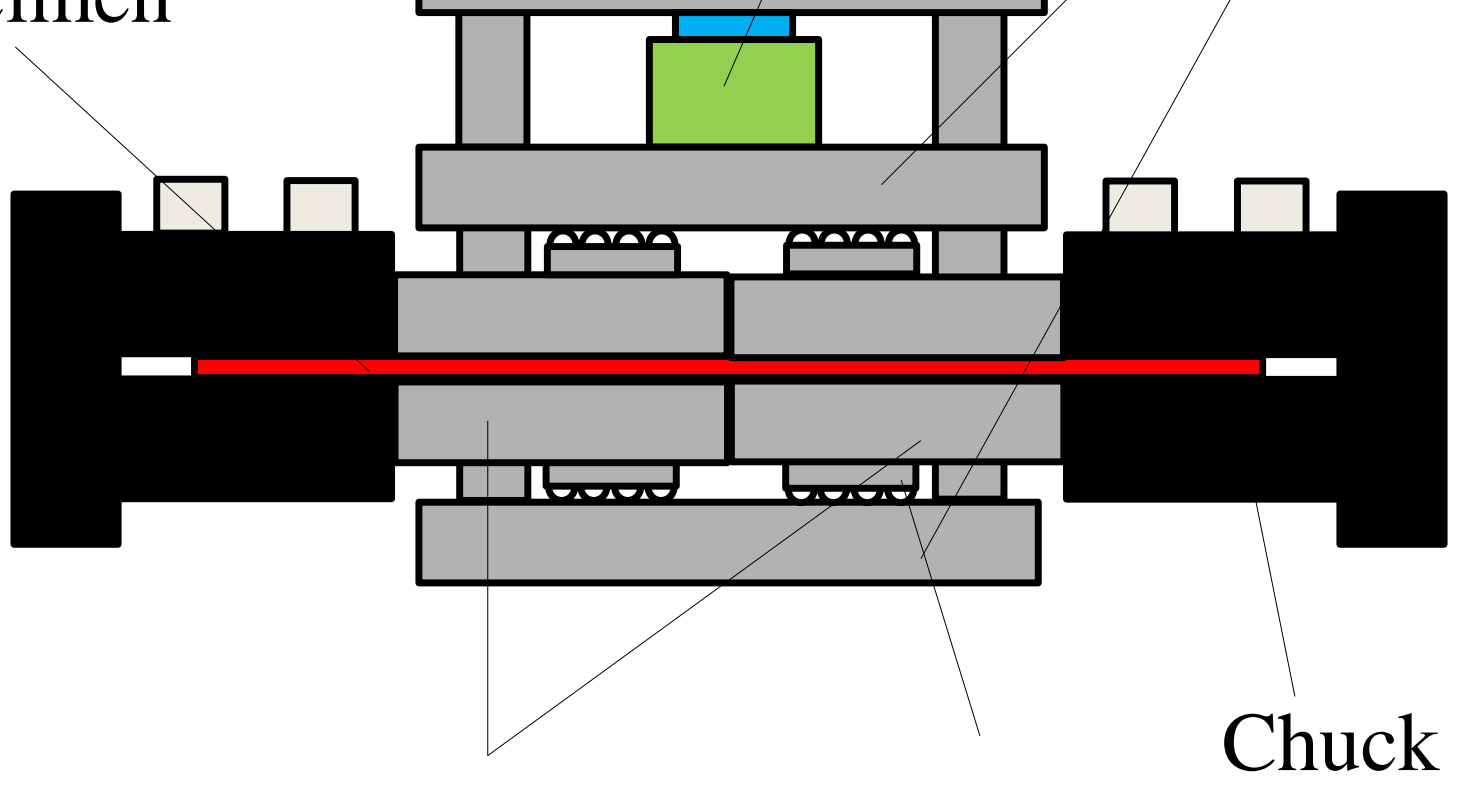

Comb-shaped dies Roller

Fig. 2. Schematic diagrams of the experimental apparatus. (a) The entire experimental setup is detailed and (b) a magnified view of the comb-shaped dies. 
(b)

\section{Comb-shaped dies}

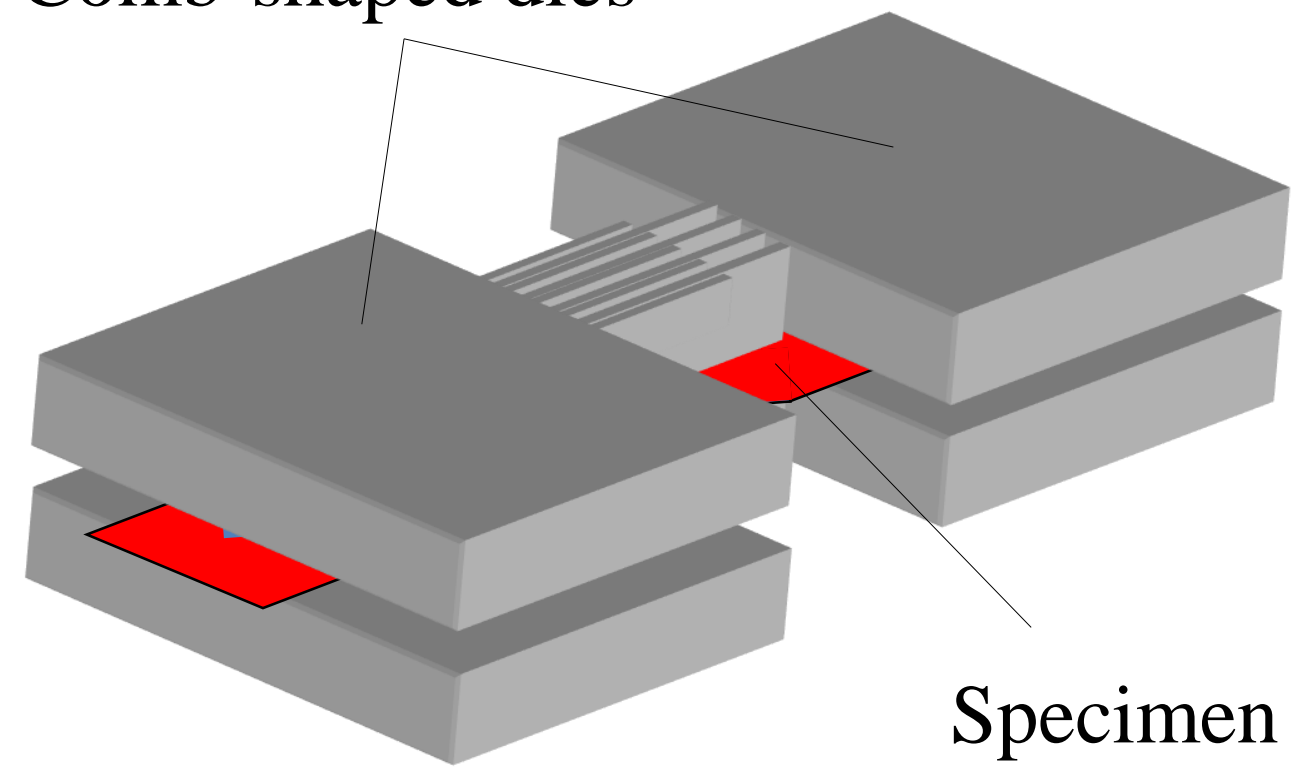

Fig. 2. Schematic diagrams of the experimental apparatus. (a) The entire experimental setup is detailed and (b) a magnified view of the comb-shaped dies. 


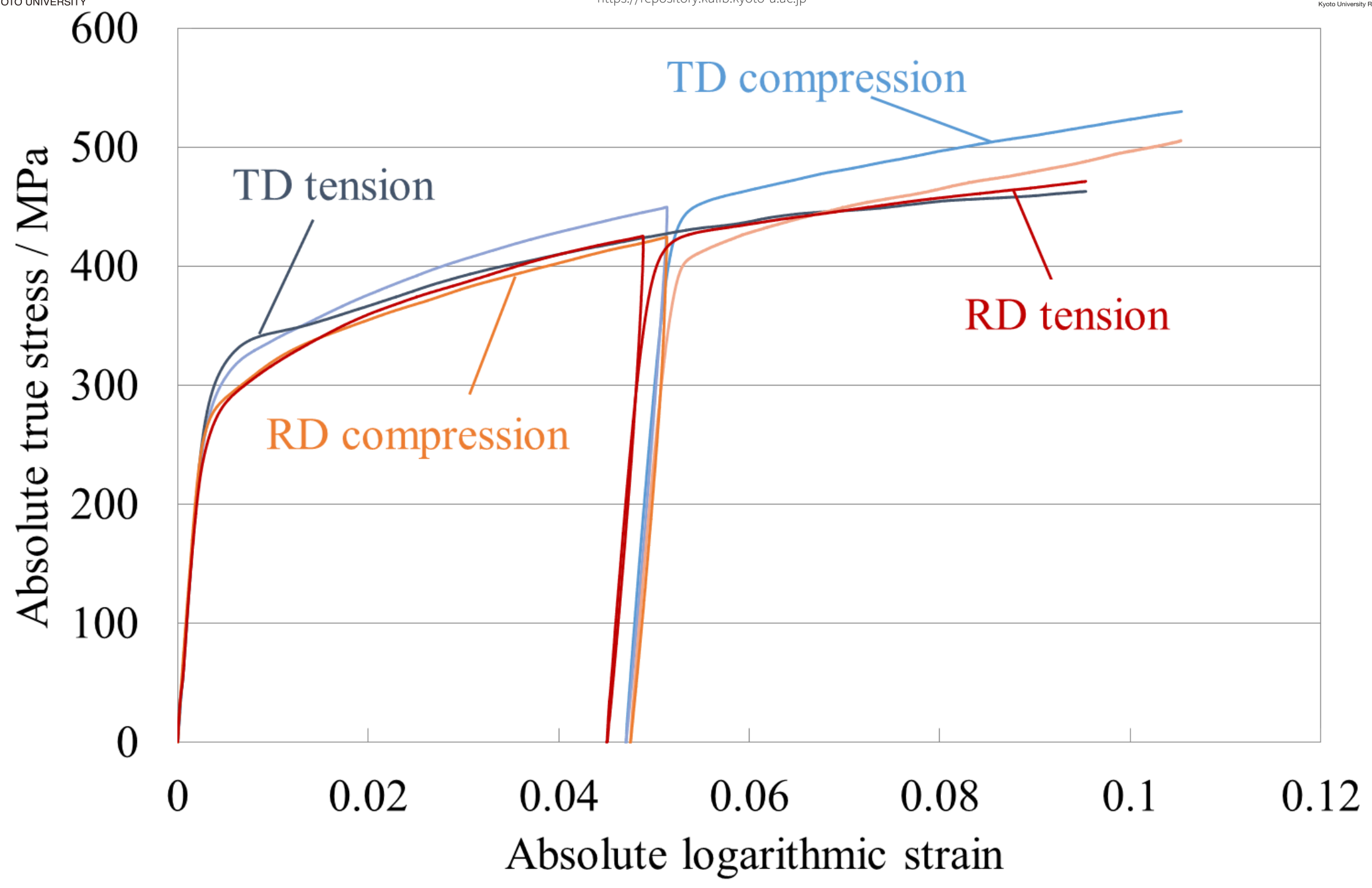

Fig. 3. True stress-logarithmic strain curves obtained under monotonic tension and monotonic compression for the rolling direction (RD) and transverse direction (TD) samples. The stress and the strain are in absolute values. 


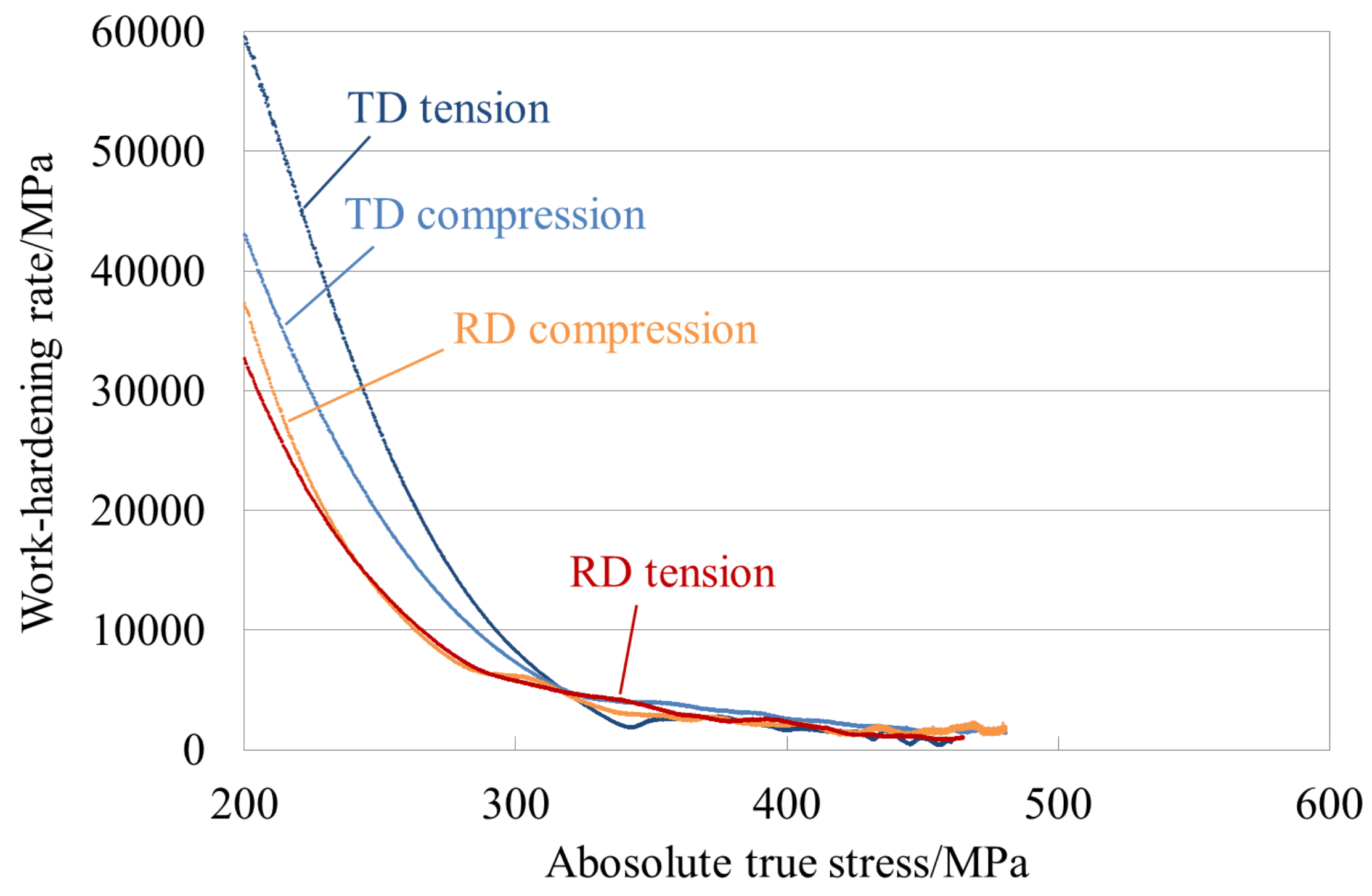

Fig. 4. Variations of the work-hardening rate as a function of stress during monotonic tension and monotonic compression for the rolling direction (RD) and the transverse direction (TD) samples. 


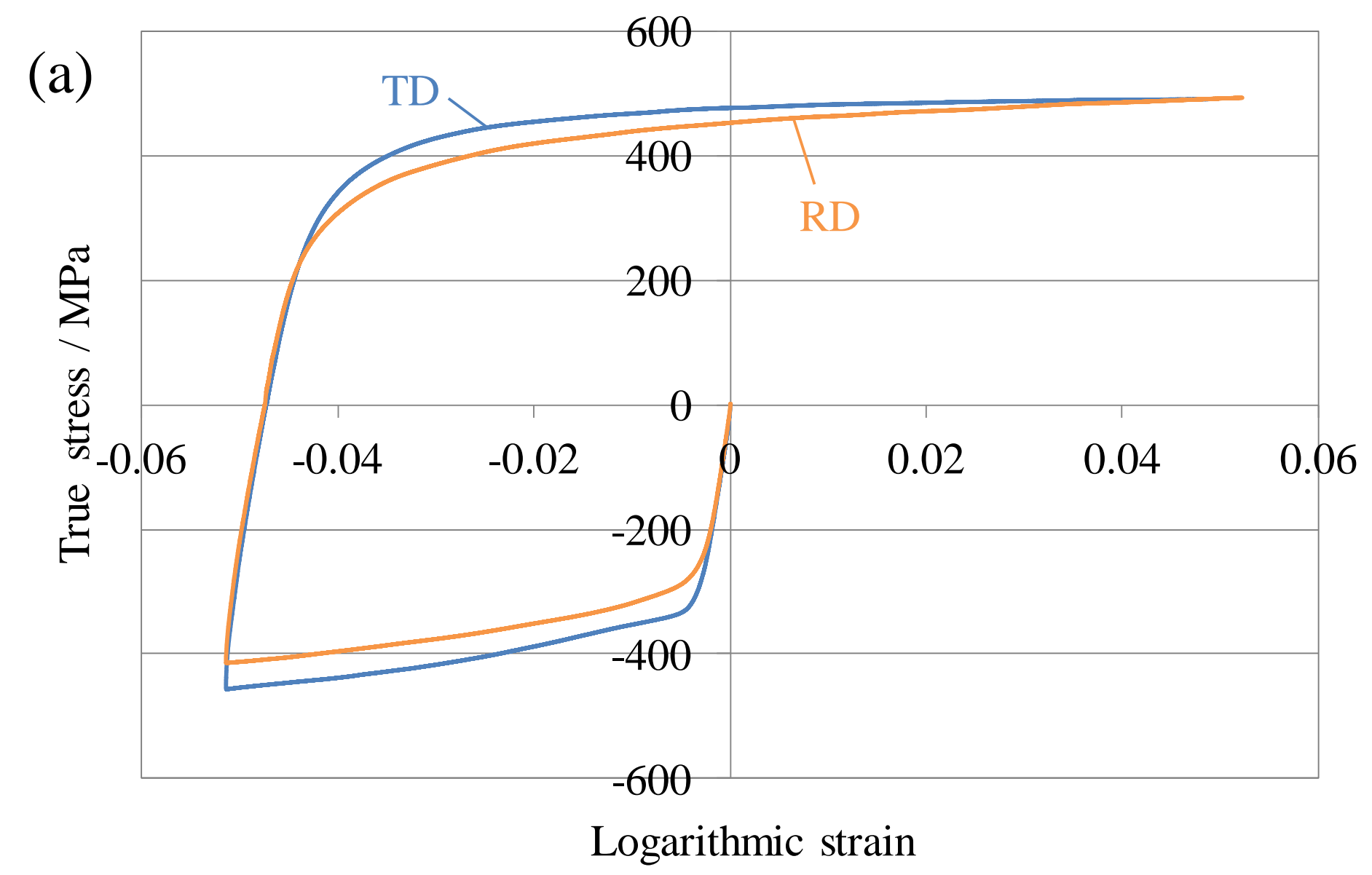

Fig. 5. True stress-logarithmic strain curves obtained under reverse loading for the rolling direction (RD) and the transverse direction (TD) samples. The magnitude of strain imparted before the loading direction was inverted was approximately 0.05. (a) Compression-tension $(\mathrm{CT})$, (b) tension-compression (TC), and (c) both results where signs of stress and strain for tension-compression were inverted. 


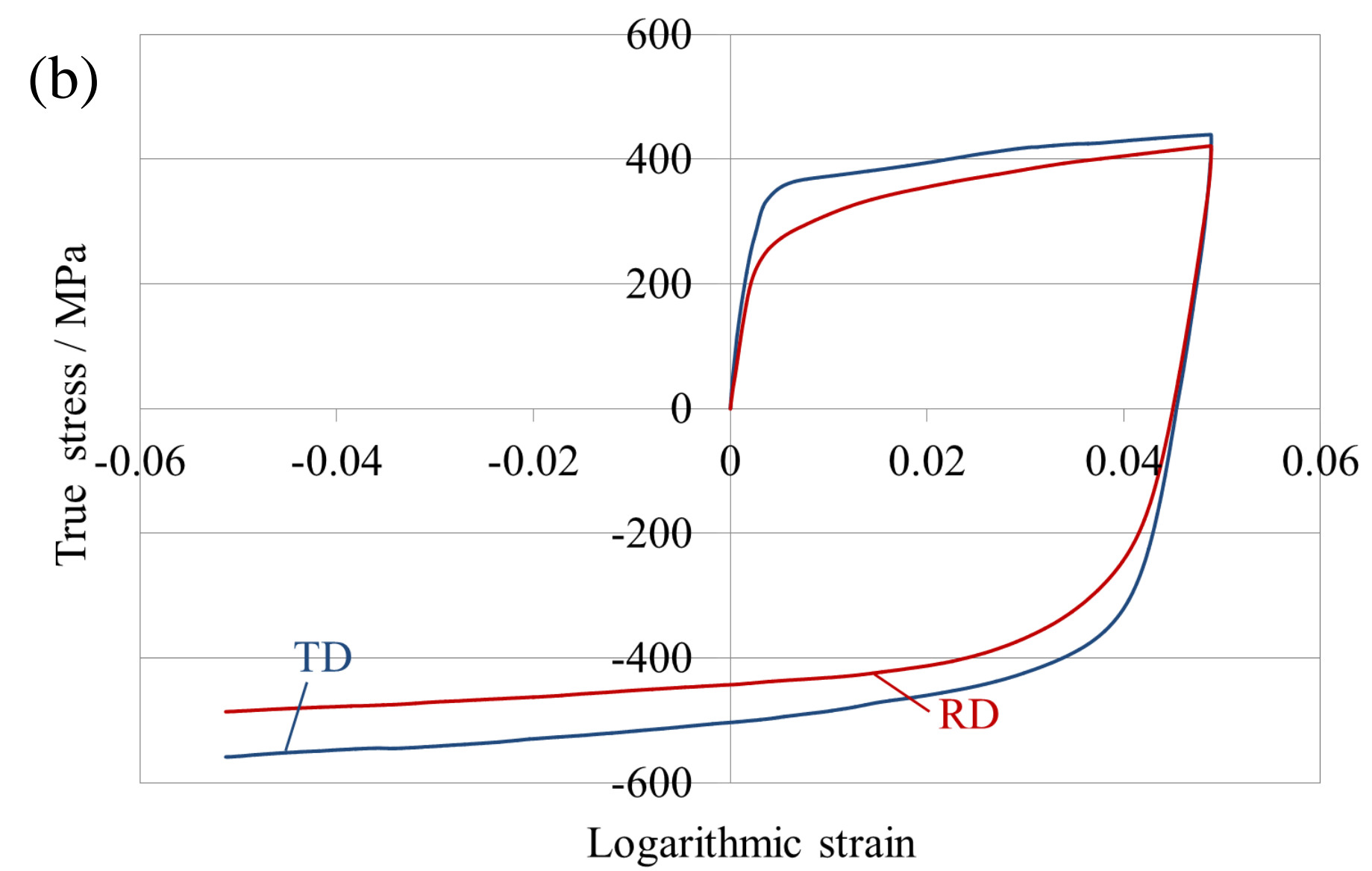

Fig. 5. True stress-logarithmic strain curves obtained under reverse loading for the rolling direction (RD) and the transverse direction (TD) samples. The magnitude of strain imparted before the loading direction was inverted was approximately 0.05. (a) Compression-tension $(\mathrm{CT})$, (b) tension-compression (TC), and (c) both results where signs of stress and strain for tension-compression were inverted. 


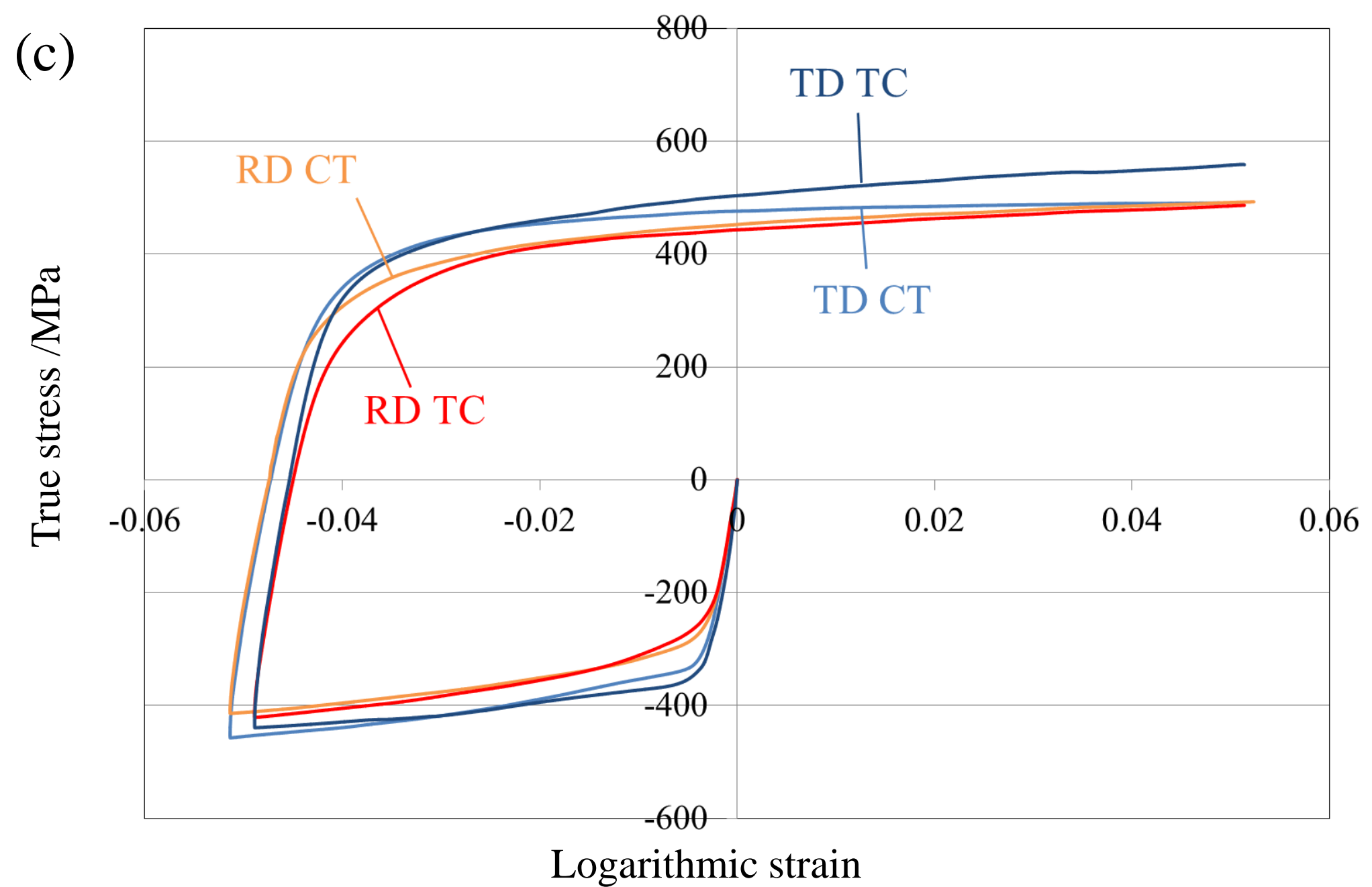

Fig. 5. True stress-logarithmic strain curves obtained under reverse loading for the rolling direction (RD) and the transverse direction (TD) samples. The magnitude of strain imparted before the loading direction was inverted was approximately 0.05. (a) Compression-tension $(\mathrm{CT})$, (b) tension-compression (TC), and (c) both results where signs of stress and strain for tension-compression were inverted. 


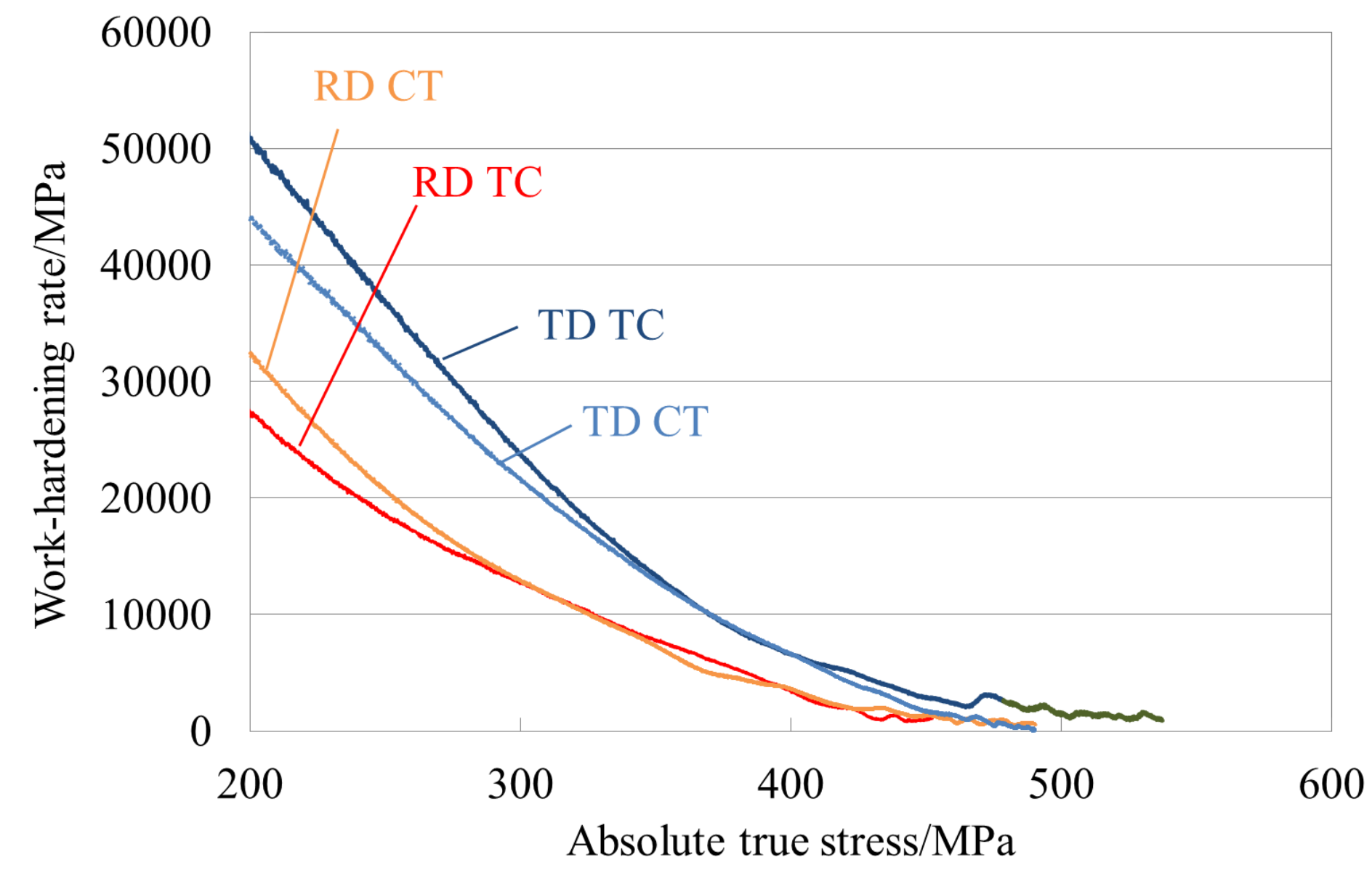

Fig. 6. Variations of work-hardening rate as a function of stress during reverse loading. The magnitude of strain imparted before the loading direction was inverted was approximately 0.05 . The results after the loading direction was inverted are shown. $\mathrm{RD}=$ rolling direction; $\mathrm{TD}=$ transverse direction; $\mathrm{CT}=$ compression-tension; $\mathrm{TC}=$ tension-compression. 


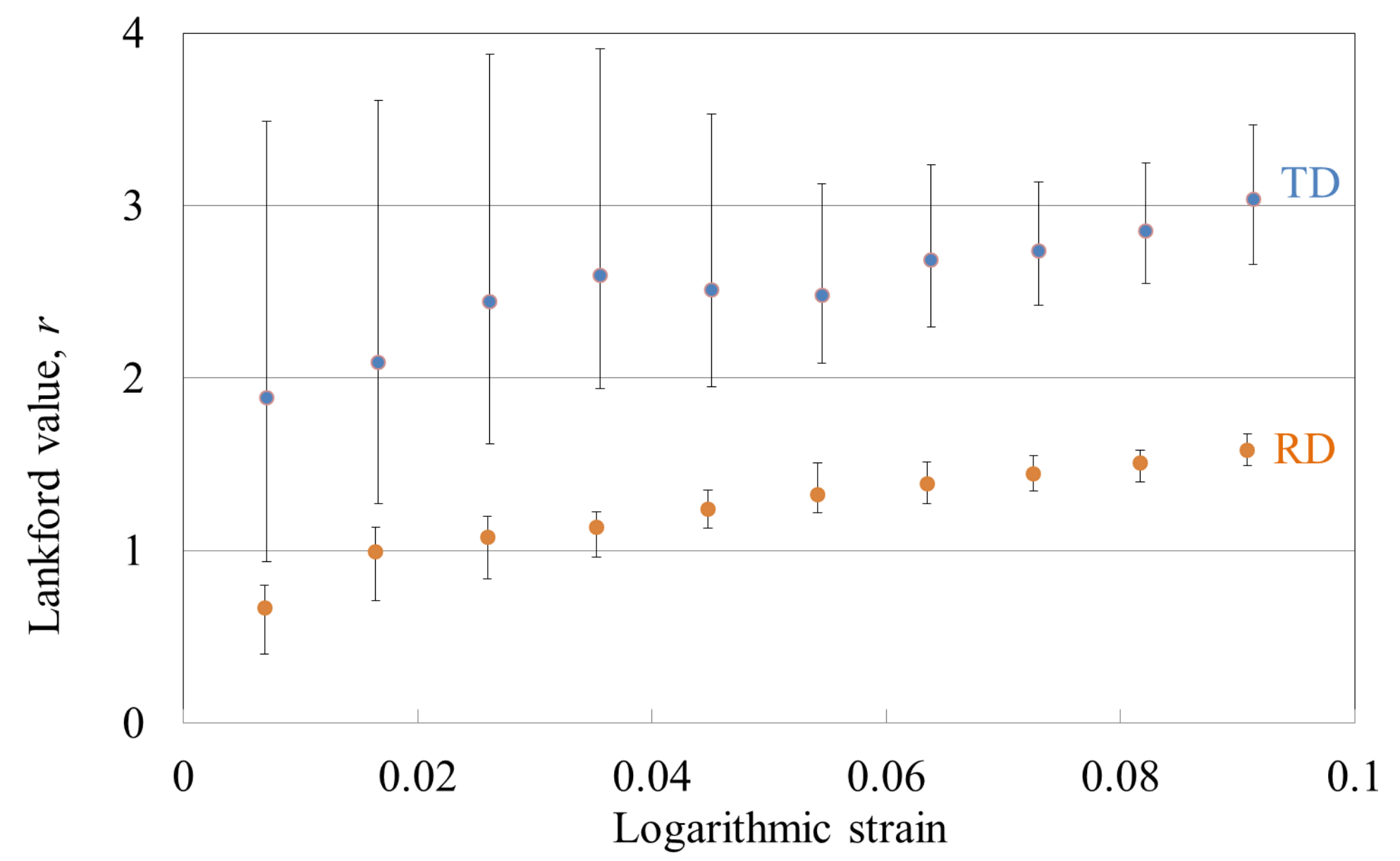

Fig. 7. Evolutions of Lankford value as a function of strain obtained under monotonic tension. $\mathrm{RD}=$ rolled direction; $\mathrm{TD}=$ transverse direction. 


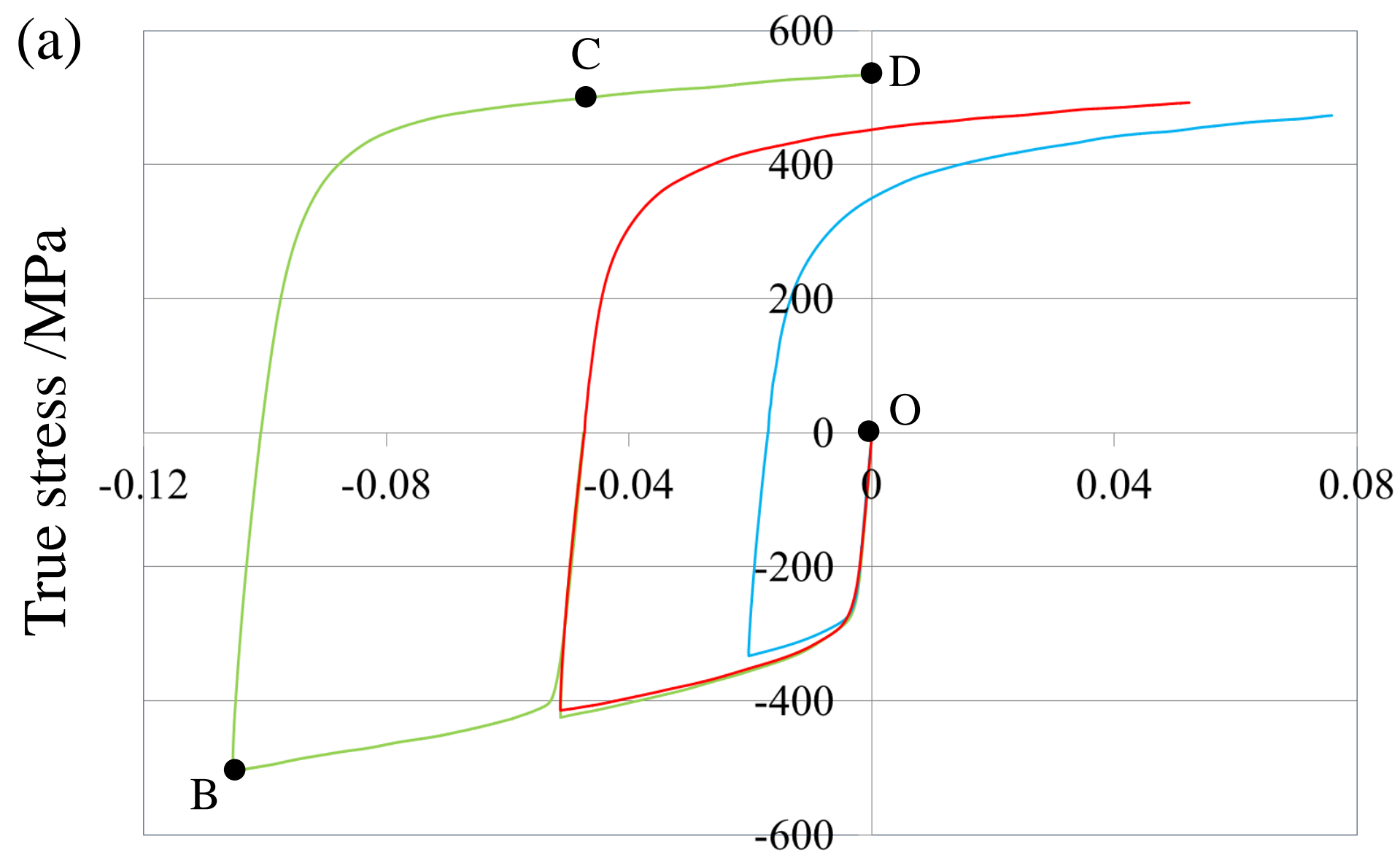

Logarithmic strain

Fig. 8. True stress-logarithmic strain curves obtained under reverse loading with various prestrains for the rolling direction (RD) sample. (a) Compression-tension (CT), (b) tensioncompression (TC), and (c) both results where signs of stress and strain were inverted for tension-compression. 


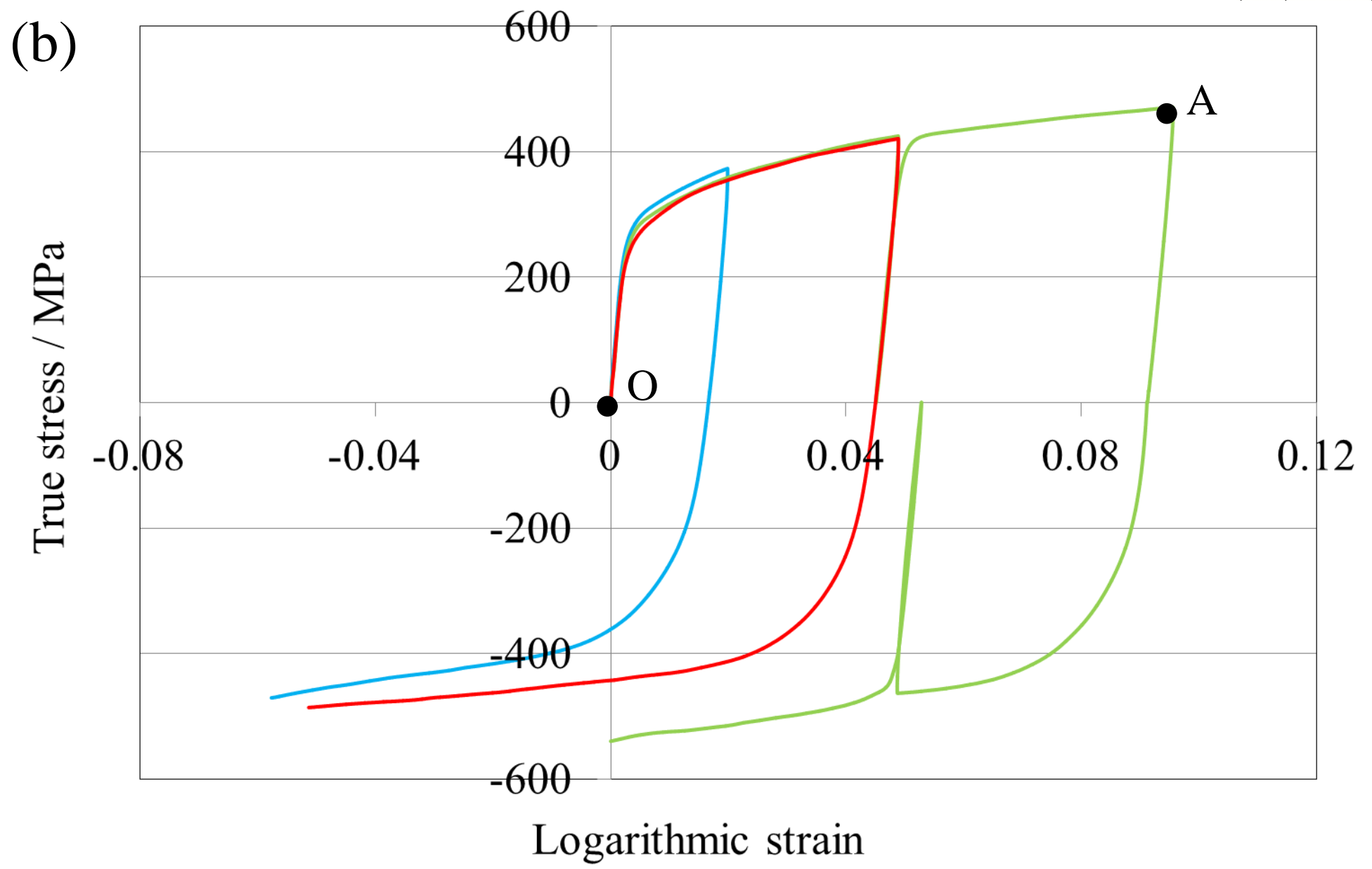

Fig. 8. True stress-logarithmic strain curves obtained under reverse loading with various prestrains for the rolling direction (RD) sample. (a) Compression-tension (CT), (b) tensioncompression (TC), and (c) both results where signs of stress and strain were inverted for tension-compression. 


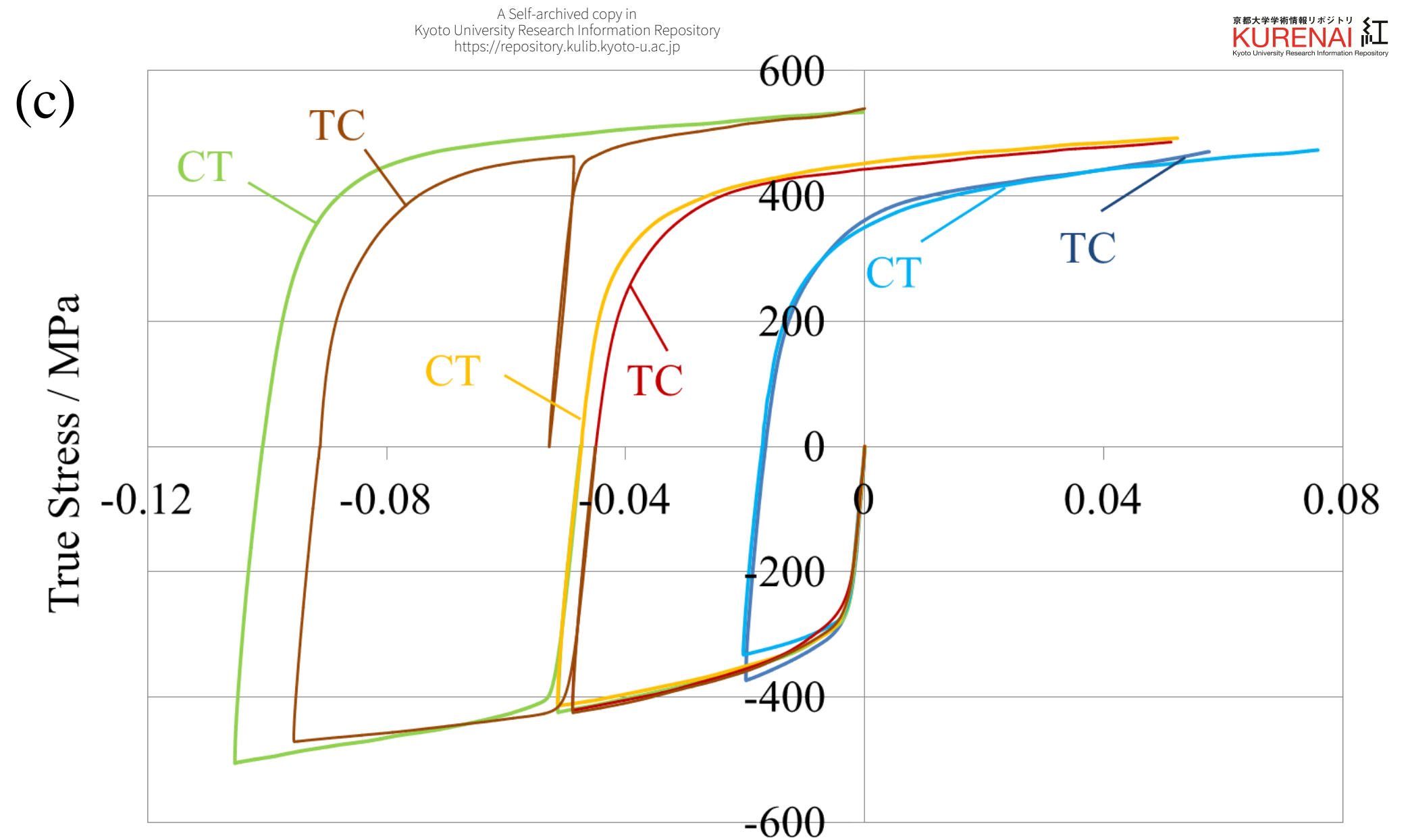

Logarithmic Strain

Fig. 8. True stress-logarithmic strain curves obtained under reverse loading with various prestrains for the rolling direction (RD) sample. (a) Compression-tension (CT), (b) tensioncompression (TC), and (c) both results where signs of stress and strain were inverted for tension-compression. 

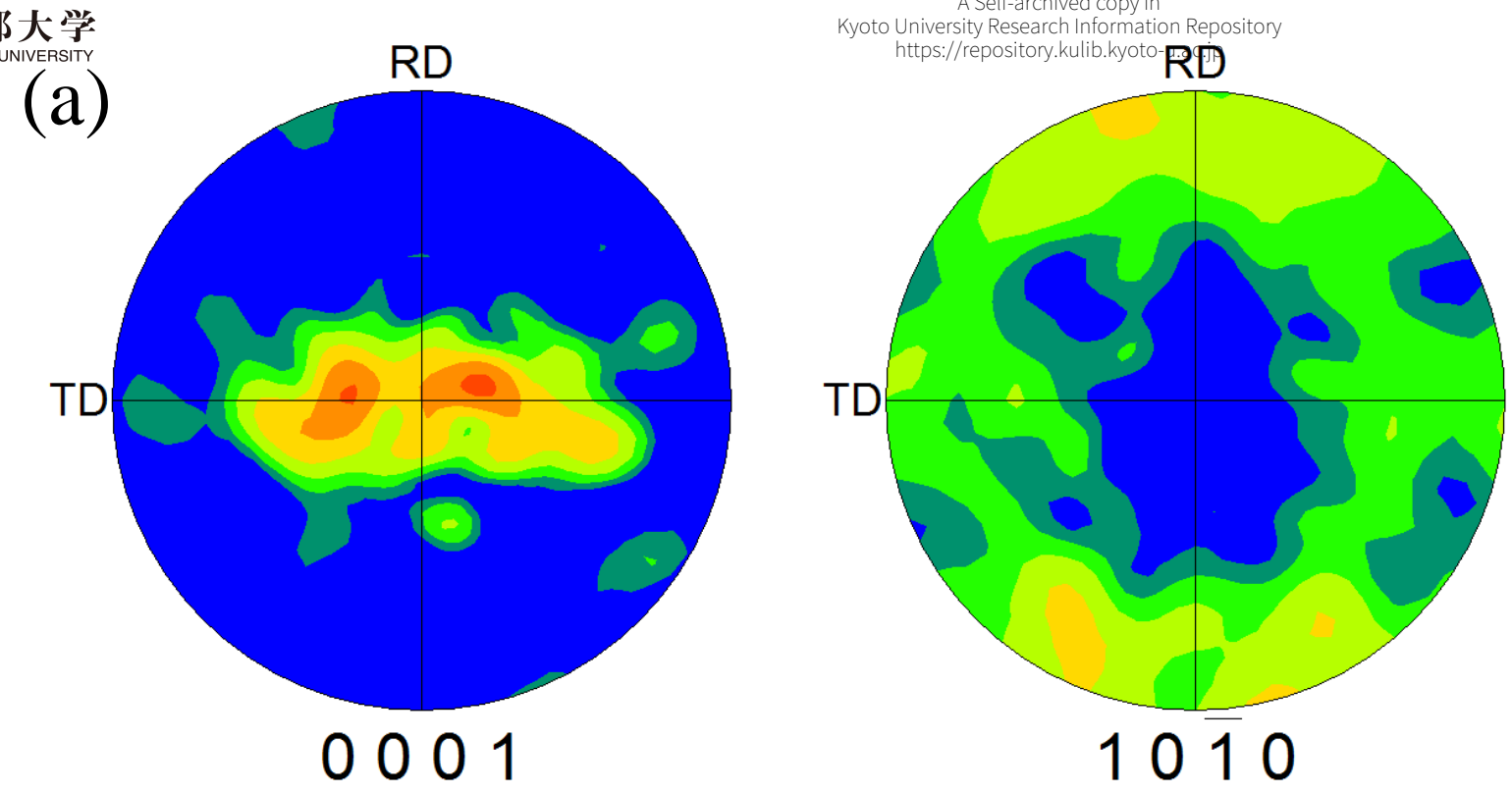

KURENAII 紅

$\max =5.329$

7.000

4.743

3.214

2.178

1.476

1.000

0.678

Fig. 9. (0001) and (10-10) pole figures for the rolling direction (RD) sample. Results are at (a) point $O$, (b) point $A,(c)$ point $B$, (d) point $C$, and (e) point D shown in Figs. 8 (a) and 8 (b). 
(b)

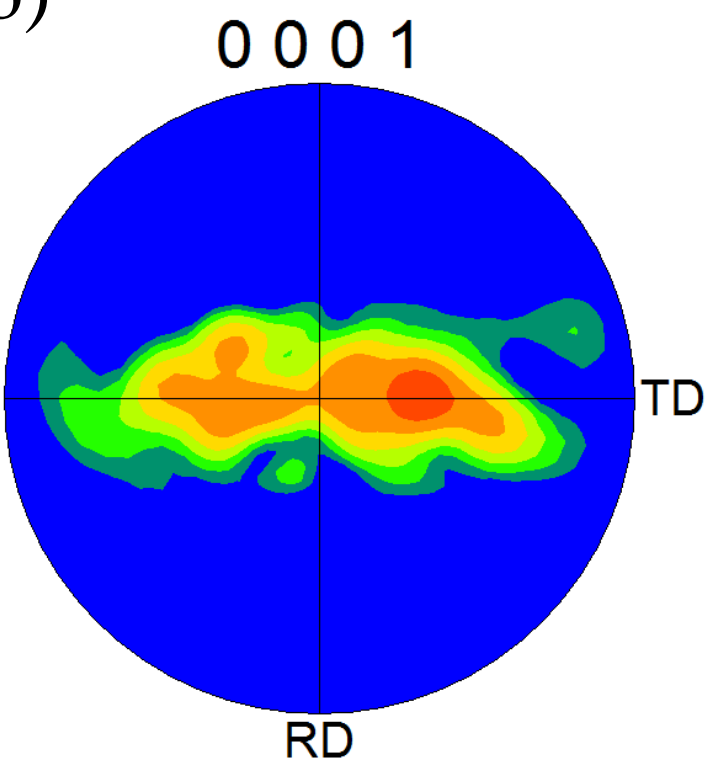

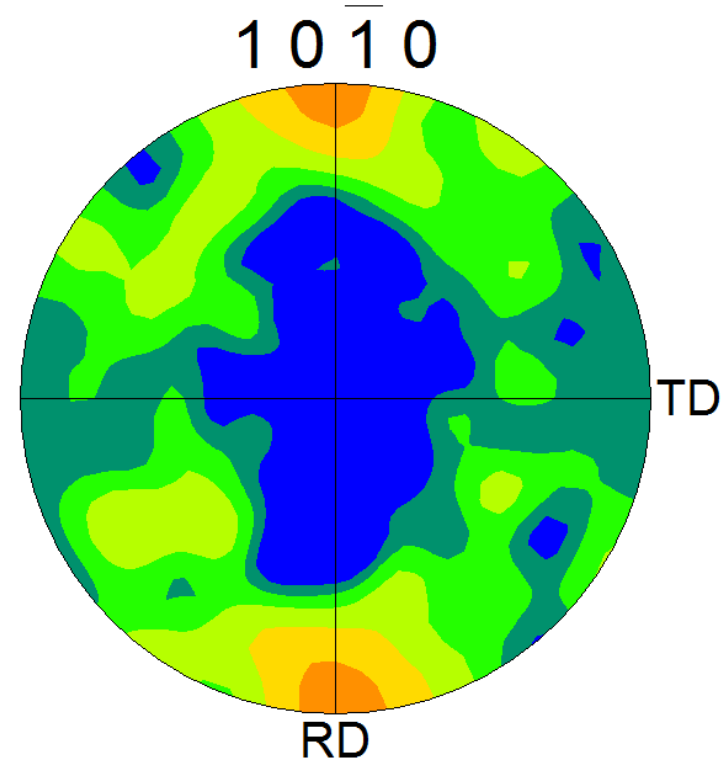

$\max =6.840$

7.000

4.743

3.214

2.178

1.476

1.000

0.678

Fig. 9. (0001) and (10-10) pole figures for the rolling direction (RD) sample. Results are at (a) point $O$, (b) point $A,(c)$ point $B$, (d) point $C$, and (e) point $D$ shown in Figs. 8 (a) and 8 (b). 

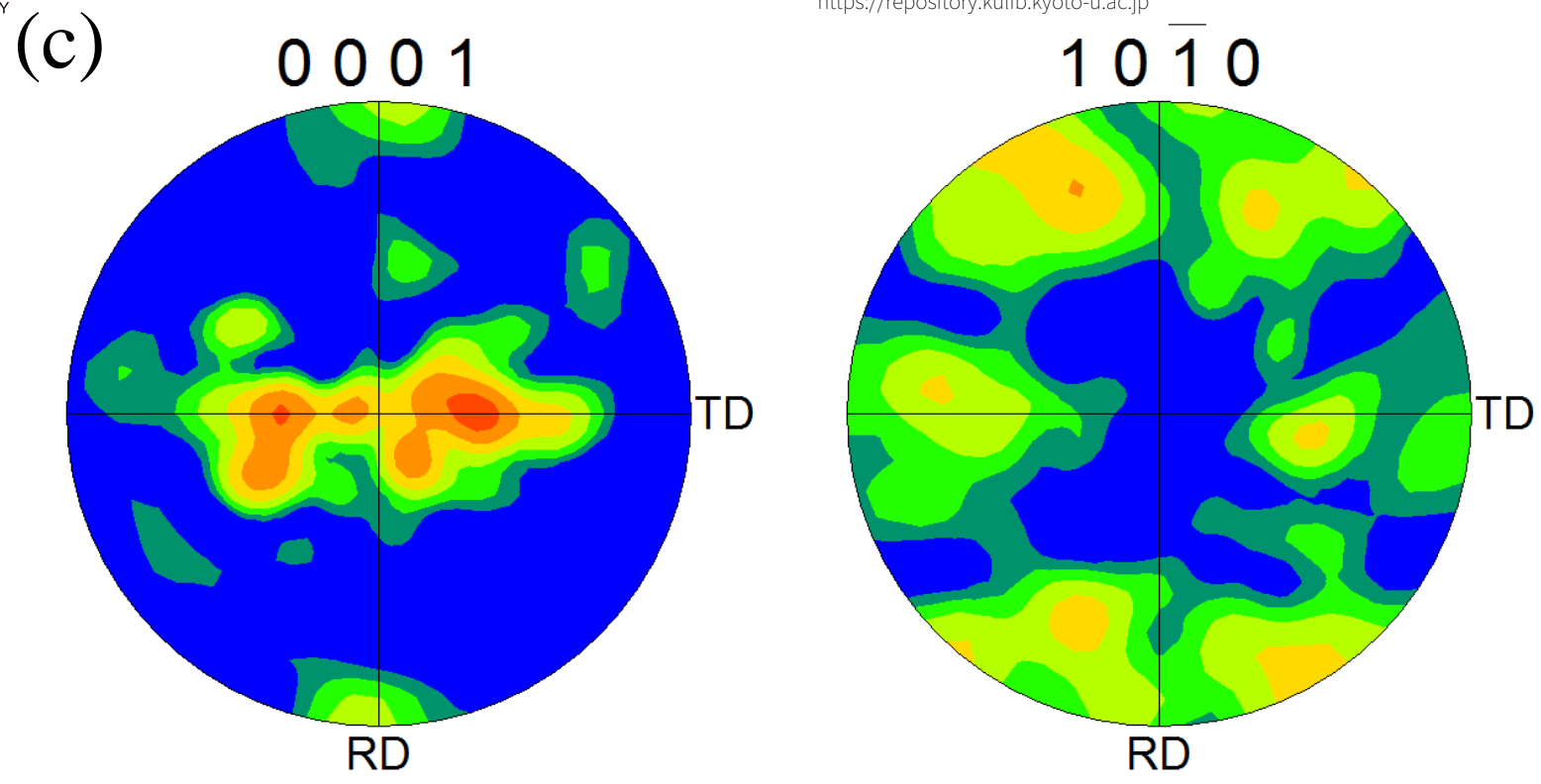

$\max =6.011$
7.000
4.743
3.214
2.178
1.476
1.000
0.678

Fig. 9. (0001) and (10-10) pole figures for the rolling direction (RD) sample. Results are at (a) point $O$, (b) point $A,(c)$ point $B,(d)$ point $C$, and (e) point $D$ shown in Figs. 8 (a) and 8 (b). 

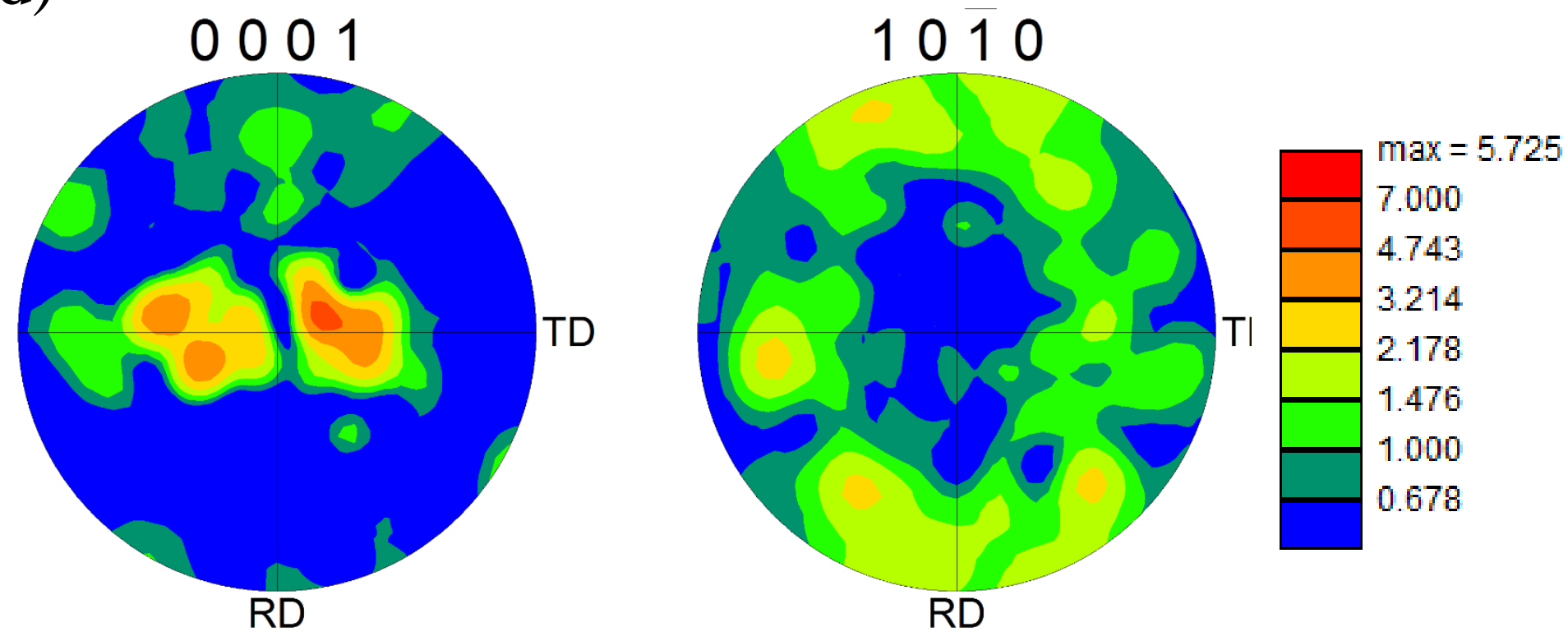

Fig. 9. (0001) and (10-10) pole figures for the rolling direction (RD) sample. Results are at (a) point $O$, (b) point $A,(c)$ point $B,(d)$ point $C$, and (e) point $D$ shown in Figs. 8 (a) and 8 (b). 
(e)
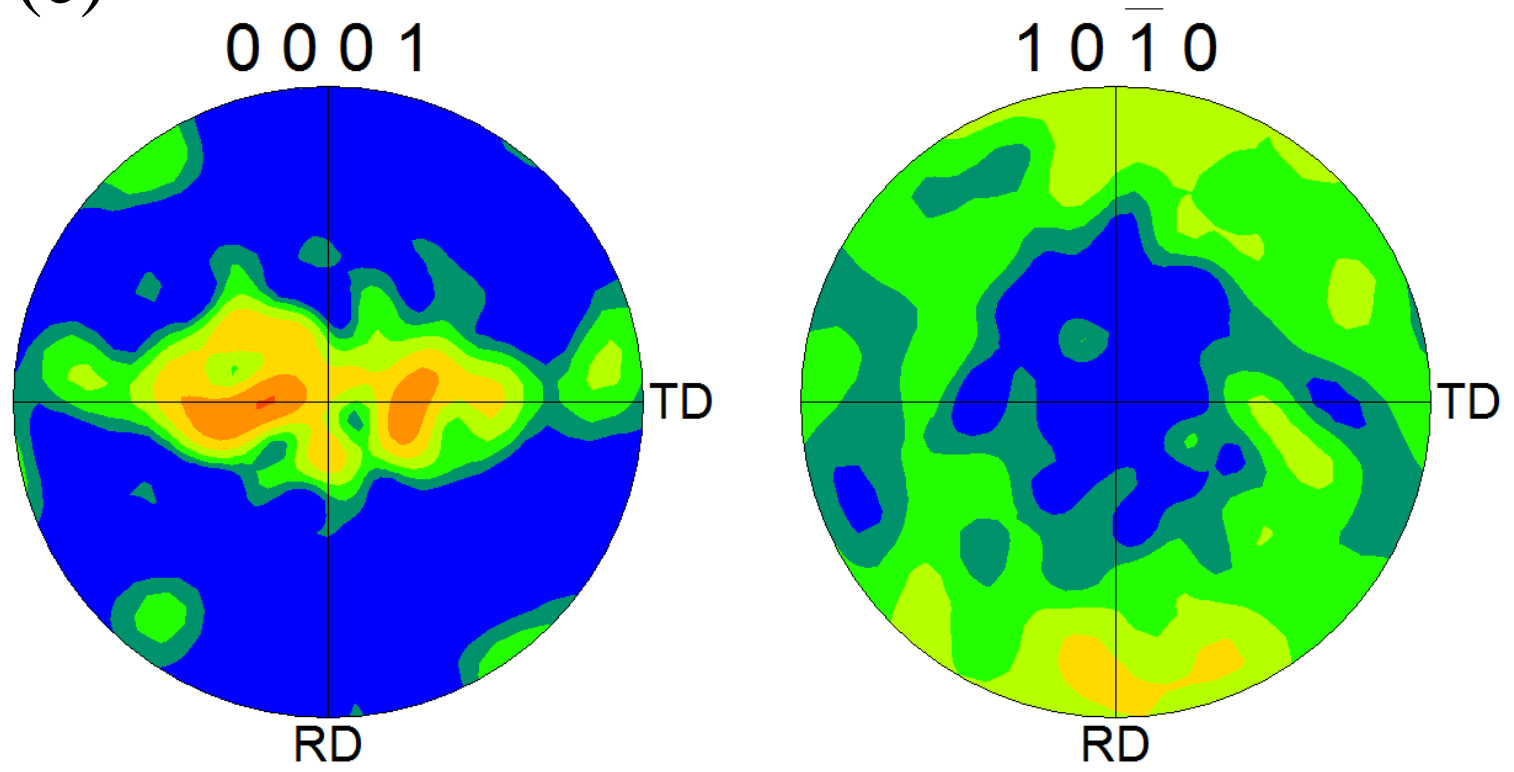

$\max =4.818$

\subsection{0}

4.743

3.214

2.178

1.476

1.000

0.678

Fig. 9. (0001) and (10-10) pole figures for the rolling direction (RD) sample. Results are at (a) point $O$, (b) point $A,(c)$ point $B$, (d) point $C$, and (e) point $D$ shown in Figs. 8 (a) and 8 (b). 
(a)
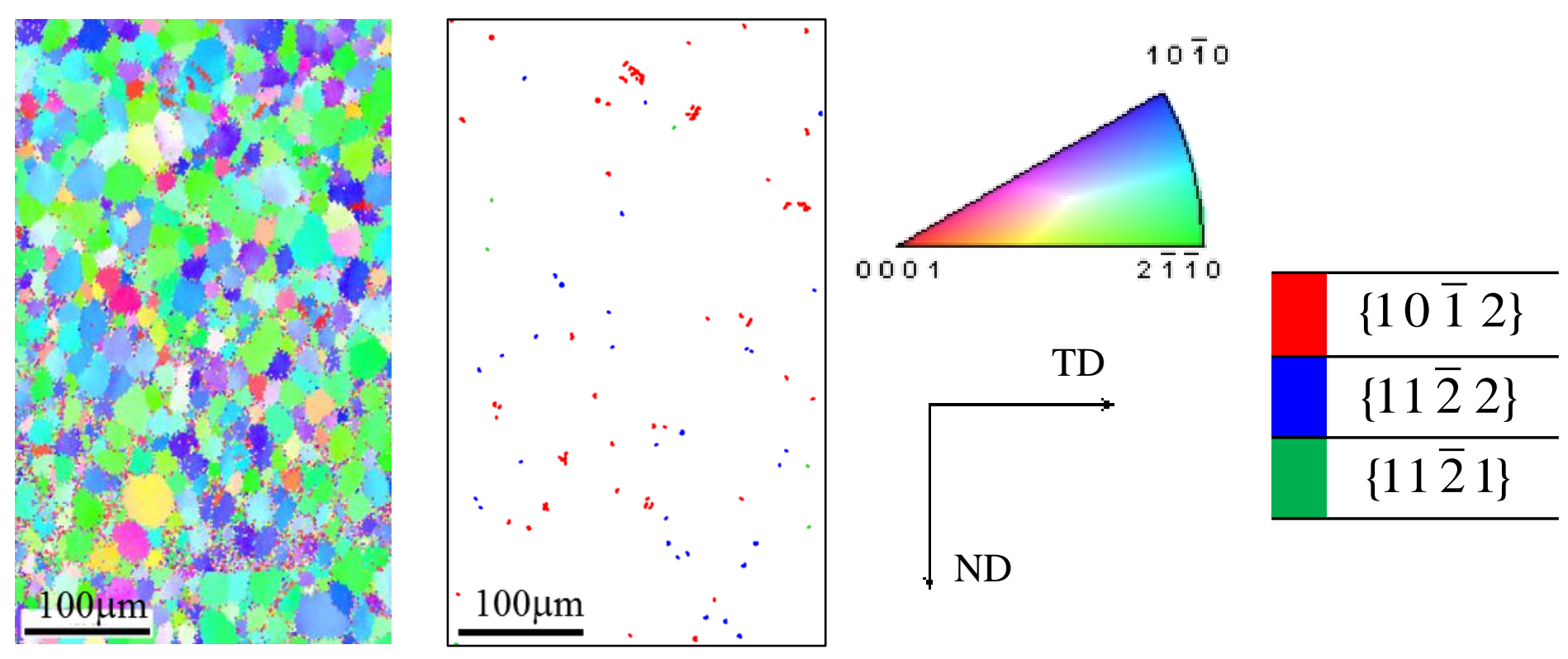

Fig. 10. Inverse pole figures and extracted twin boundaries for the rolling direction (RD) sample. Results are at (a) point $O$, (b) point $A,(c)$ point $B,(d)$ point $C$, and (e) point D shown in Figs. 8 (a) and 8 (b). TD = transverse direction. 
(b)
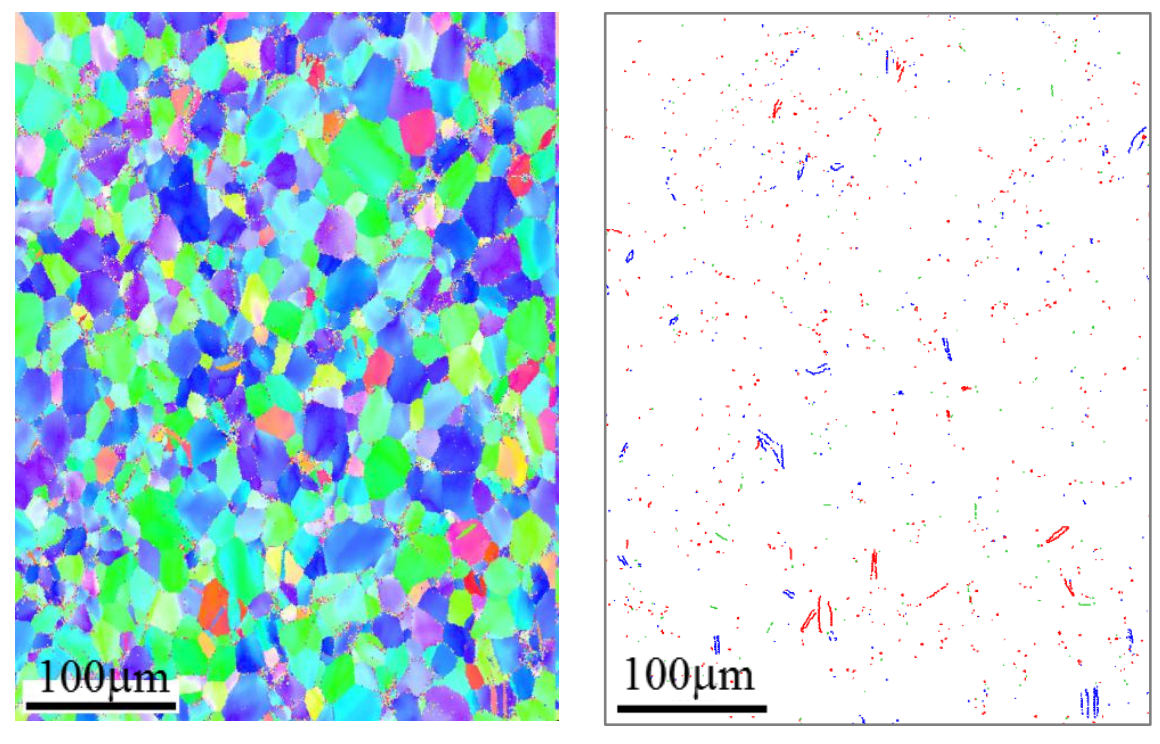

Fig. 10. Inverse pole figures and extracted twin boundaries for the rolling direction (RD) sample. Results are at (a) point $O$, (b) point $A$, (c) point $B$, (d) point $C$, and (e) point D shown in Figs. 8 (a) and 8 (b). TD = transverse direction. 
(c)
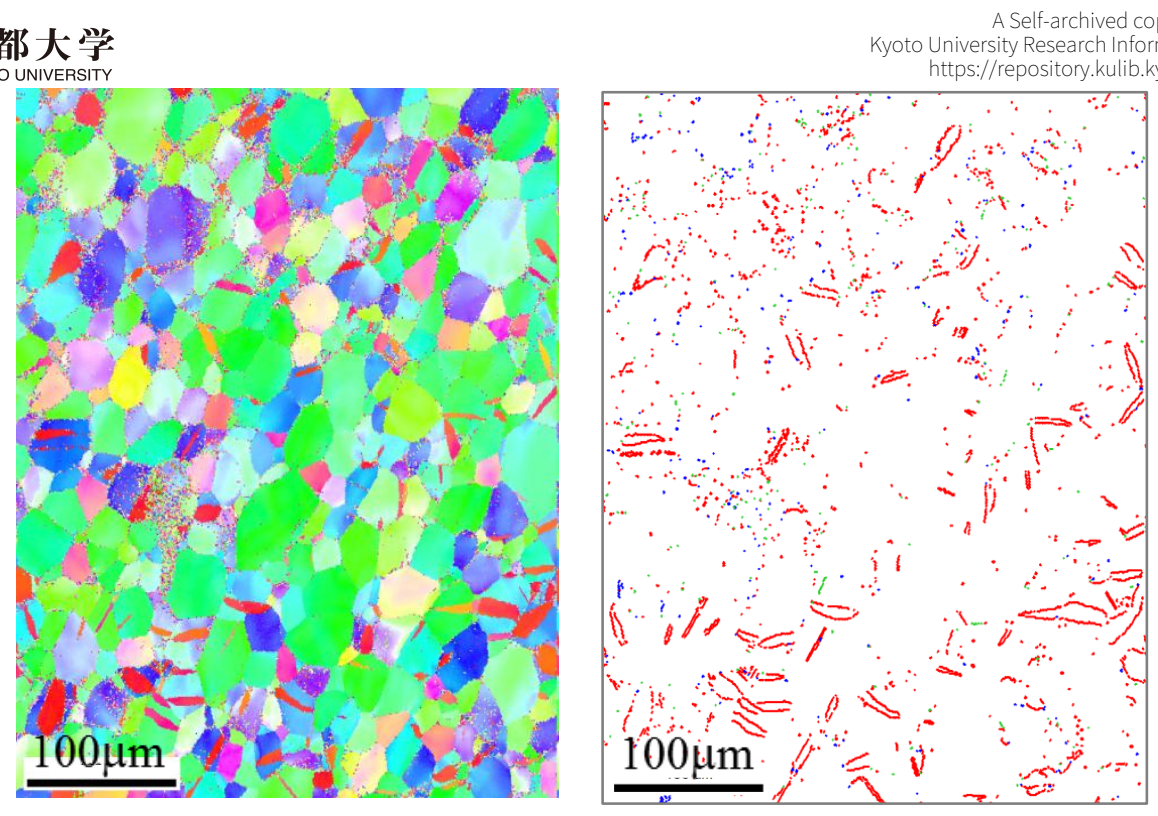

Fig. 10. Inverse pole figures and extracted twin boundaries for the rolling direction (RD) sample. Results are at (a) point $O$, (b) point $A,(c)$ point $B,(d)$ point $C$, and (e) point $D$ shown in Figs. $8(a)$ and 8 (b). TD = transverse direction. 
(d)

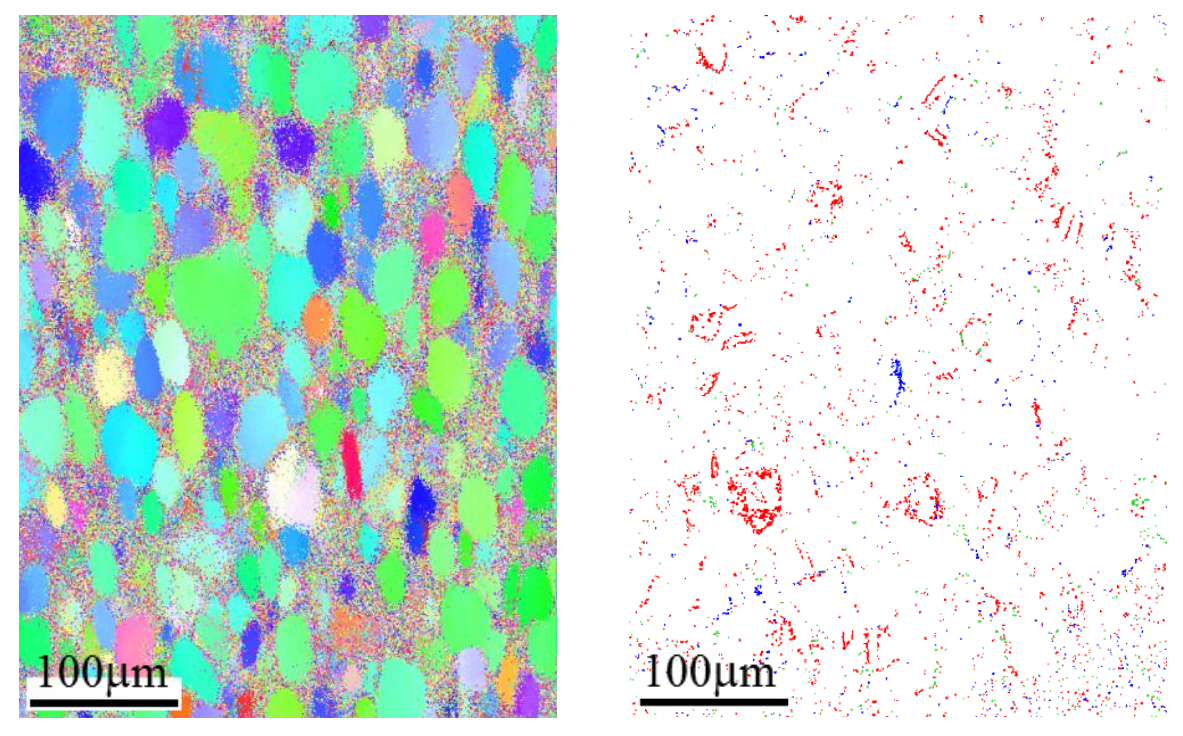

Fig. 10. Inverse pole figures and extracted twin boundaries for the rolling direction (RD) sample. Results are at (a) point $O$, (b) point $A,(c)$ point $B,(d)$ point $C$, and (e) point D shown in Figs. 8 (a) and 8 (b). TD = transverse direction. 
(e)
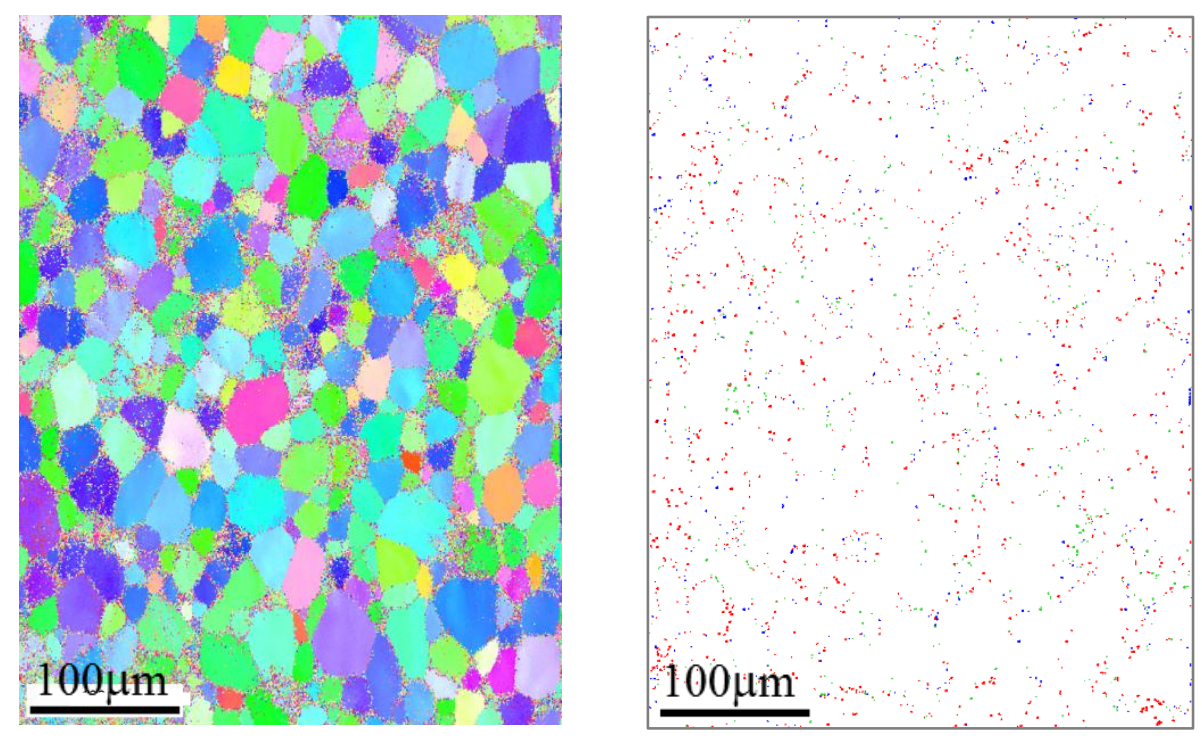

Fig. 10. Inverse pole figures and extracted twin boundaries for the rolling direction (RD) sample. Results are at (a) point $O$, (b) point A, (c) point B, (d) point C, and (e) point $D$ shown in Figs. 8 (a) and 8 (b). TD = transverse direction. The inverse pole figures were plotted with respect to the loading direction RD. 

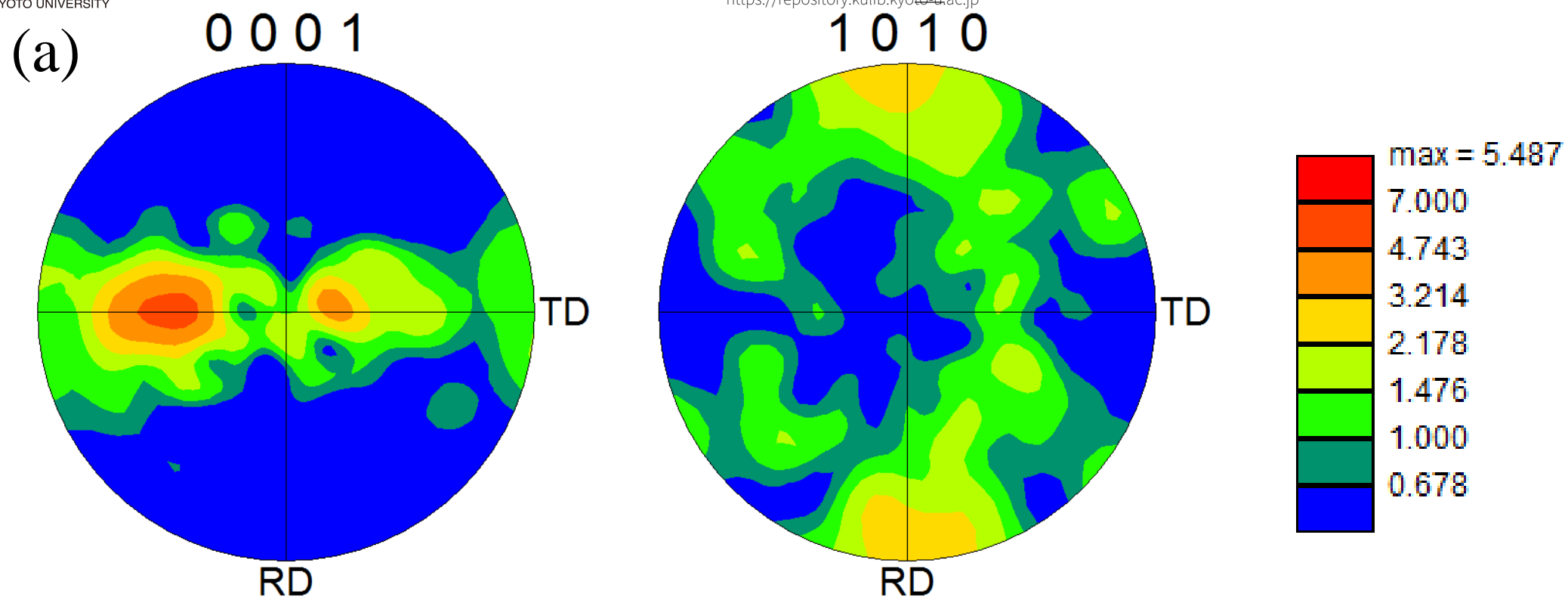

Fig. 11. Results of microstructure observation at point B (Fig. 8 (b)) for the transverse direction (TD) sample. (a) Pole figures, and (b) inverse pole figures and extracted twin boundaries. $\mathrm{RD}=$ rolling direction. 

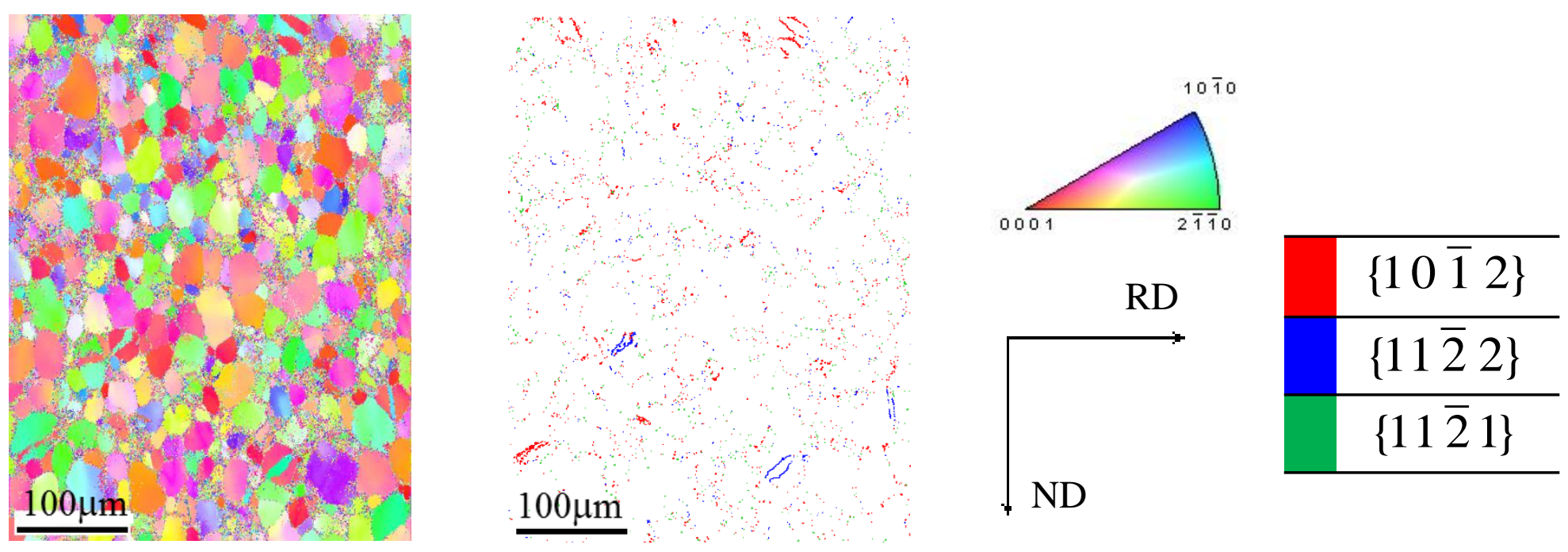

Fig. 11. Results of microstructure observation at point B (Fig. 8 (b)) for the transverse direction (TD) sample. (a) Pole figures, and (b) inverse pole figures and extracted twin boundaries. RD = rolling direction. The inverse pole figure was plotted with respect to the loading direction TD. 